\title{
From flood risk mapping toward reducing vulnerability: the case of Addis Ababa
}

\author{
Raffaele De Risi ${ }^{1}$. Fatemeh Jalayer ${ }^{2}$. Francesco De Paola ${ }^{3}$. Stefano Carozza ${ }^{2}$. \\ Nebyou Yonas ${ }^{4} \cdot$ Maurizio Giugni $^{3} \cdot$ Paolo Gasparini ${ }^{5}$
}

Received: 22 December 2018 / Accepted: 23 October 2019 / Published online: 2 November 2019

(c) The Author(s) 2019

\begin{abstract}
Flood risk maps for the built environment can be obtained by integrating geo-spatial information on hazard, vulnerability and exposure. They provide precious support for strategic urban planning and decision-making. These maps, generated in a probabilistic framework, can consider various sources of uncertainty in the flood risk assessment such as the occurrence of extreme flooding events, future land use and land cover, characteristics of the buildings, and exposure to flooding. This paper investigates how these maps can be used in complicated urban context such as developing countries, where engineers are forced to work with scarce or little data. Specifically, a detailed investigation on the city of Addis Ababa, Ethiopia, has been conducted. Although the city of Addis Ababa is undergoing extensive formal housing development, it is most likely that the informal settlements will continue to constitute a significant portion of urban housing landscape in the years to come. Recent research findings and field work from a large project (FP7-CLUVA) are employed in order to provide a quantified basis for decision-making between alternative adaptation strategies for informal buildings in Addis Ababa. Risk maps, obtained by upscaling more accurate risk assessment results at neighborhood level, are adopted for risk zoning of the urban residential texture within the city. This provides risk-based criteria for both identifying suitable flood adaptation strategies and prioritizing between viable risk mitigation measures.
\end{abstract}

Keywords Extreme meteorological events $\cdot$ Rainfall-induced flooding $\cdot$ Flood risk $\cdot$ Risk zoning $\cdot$ Exposure $\cdot$ Urban morphology type $\cdot$ Fragility $\cdot$ Informal settlements $\cdot$ Africa

Raffaele De Risi

raffaele.derisi@bristol.ac.uk

1 Department of Civil Engineering, University of Bristol, Queen's Building, University Walk, Clifton BS8 1TR, UK

2 Department of Structures for Engineering and Architecture, University of Naples Federico II, Naples, Italy

3 Department of Civil, Architectural and Environmental Engineering, University of Naples Federico II, Naples, Italy

4 Ethiopian Institute of Architecture, Building Construction and City Development, Addis Ababa, Ethiopia

5 Analysis and Monitoring of Environmental Risks (AMRA), Scarl, Naples, Italy 


\section{Introduction}

Despite the rapid progress of scientific knowledge and the increasing awareness of disaster risk and management, the social and economic impact of natural disasters is increasing. In fact, in the last decades, weather-related disasters alone have been the cause of between 70 and 90 percent of the total number of natural disasters around the world (Hoyois and GuhaSapir 2012). Floods in particular, are responsible for around $60 \%$ of the total population affected, and for almost $10 \%$ of the total economic losses due to natural disasters (CRED 2012). The increasing evidence in favor of correlation between climate change and extreme weather-related phenomena (Khan and Kelman 2012; Jalayer et al. 2013a) paired up with rapid rate of urbanization leads to an increase in risk due to future weather-related phenomena in urban areas. In fact, half of the world's population currently lives in urban areas; this ratio is estimated to rise up to around $70 \%$ by 2050 (UN Habitat 2010). Being less resilient to natural disasters (due to several factors such as, fragile economy, poverty, lack of risk awareness, and lack of coping capacity), the urban areas in sub-Saharan Africa are particularly vulnerable to weather-related phenomena. The informal settlements (a.k.a., slums, shanty towns, squatter settlements), which exist as a direct consequence of unplanned and disproportional urban growth and are characterized by poor or non-existing construction standard (De Risi et al. 2013a), are usually located in high-risk areas such as river banks and flood plains (Sakijege et al. 2014). Considering that somewhere between 60 and $70 \%$ of the urban population in sub-Saharan Africa lives in existing informal settlements, the urban decision makers need to pay specific attention to their exposure to risk.

In this context, identification of flooding risk hotspots (e.g., Jalayer et al. 2014; De Risi et al. 2014; De Risi et al. 2018a) constitutes a significant step. The hotspots are areas potentially experiencing high financial losses and causalities and, as such, necessitate immediate or long-term mitigation actions. Mitigation strategies include urban planning, relocation policies (if applicable), territory restriction measures, and actions aiming at increasing public awareness (Jalayer et al. 2014, 2015; De Risi et al. 2018b). Reliable prediction of the adverse effects of weather-related phenomena in terms of risk mapping is a fundamental basis for adaption and decision-making strategies. In fact, maps represent a straightforward tool for representation of spatial distribution of flood risk with respect to alternative representations such as verbal description or complicated charts (Merz et al. 2007). Flood risk mapping is the starting point of any regional intervention policy, such as (a) land use planning, (b) development of new urban areas, (c) assessment of flooding risk reduction benefits, (d) identification of the feasibility of non-structural flood control measures, (e) insurance planning, (f) investment planning and priority setting, mainly for non-structural measures, (g) increasing public awareness of risk (Marco 1994).

Apel et al. (2009) provided a comprehensive study on various scales of complexity and accuracy involved in flood risk assessment. In fact, flooding risk maps may be produced at different spatial scales, ranging from macroscale level (i.e. regional level, typically less than 1:100,000), up to mesoscale level (i.e. city level, typically less than 1:10,000), or to microscale level (i.e. neighbor level, typically ranging between 1:10,000 and 1:1000). The accuracy of the methods adopted for flood risk assessment should be compatible with the level of detail in terms of spatial scale of the input data (e.g., hazard, exposure and vulnerability maps) and of the output (i.e., risk map) representation.

Flood hazard maps provide the spatial distribution of the adopted flood intensity measure for a given return period or hazard level. Intensity measures typically adopted for flooding are the inundation depth and the inundation velocity. In the last decade, two kind of 
methodologies have been developed in order to produce flood hazard maps; (a) procedures based on physically based hydraulic models (Domeneghetti et al. 2012; Teng et al. 2017) and (b) procedures based on basin's geomorphologic features (e.g., Degiorgis et al. 2012; De Risi et al. 2015; Samela et al. 2016, 2018). Physically based hydraulic models provide the flood depth and the velocity for each point within the study area for various critical rainfall scenarios usually identified by duration and the return period of the rainfall (De Paola et al. 2014). These procedures can consider the presence of buildings, infrastructures, and vegetation characteristics (Yang et al. 2015; Biscarini et al. 2013; Fabio et al.2010; Aronica et al. 1998; Cobby et al. 2003; O'Brien et al. 1993). The physically based hydraulic methodologies are generally computationally demanding, and they require significant amount of data and parameters to describe the morphology and the surface characteristics of the flood basin (Di Baldassare et al. 2009; Bates et al. 2004; Bates and De Roo 2000). Conversely, geomorphologic procedures use the digital elevation model (DEM) as main data source. These methodologies are sensibly less accurate and thereby more suitable for large areal extents. They can use various topographic indicators as proxies for flood depth and propagation (Manfreda et al. 2014; Dodov and Foufoula-Georgiou 2006; Gallant and Dowling 2003). It is worth noting that flood hazard maps alone cannot quantify the consequences of flooding on society, built environment or natural environment. These consequences are quantified by the convolution of hazard with exposure and vulnerability to obtain risk.

Exposure maps provide a graphical representation of the elements and assets at risk (Merz et al. 2007). As such, exposure mapping may consist of spatial datasets containing information about population density, location and characteristics of buildings, infrastructure, economical activities, the urban ecosystem and points of strategic interest. Urban morphology types (UMTs) constitute a powerful instrument for the representation of built and natural environment. UMTs (Pauleit and Duhme 2000; Gill et al. 2008) form the foundation of a classification scheme bringing together facets of urban form and function. UMTs have characteristic physical features (i.e. land cover) and are differentiated on the basis of human activities they accommodate (i.e. land uses). In the assignment/definition of UMTs, physical properties and human activities are the key factors for characterization of urban areas. Once an appropriate UMT classification scheme is established for a specific study area, individual UMT units are delineated using aerial photography and other geospatial data sources. UMT units are often mapped at a "meso"'-scale (i.e., between the city level and that of the individual units). This makes them a suitable basis for the spatial analysis of cities (see e.g., Cavan et al. 2014; Jalayer et al. 2014; De Risi et al. 2018a). UMTs can be further enriched by geo-spatial census dataset (e.g., to incorporate the population density) and by the characteristics of the built environment (e.g., building footprints, infrastructure layout).

The risk maps incorporate information about hazard, exposure and vulnerability of the built environment. Vulnerability analysis can be carried out aiming at the quantification of the adverse effects induced by flooding. Vulnerability is usually represented by fragility functions, which describe the probability of exceedance of a prescribed damage state given the flood intensity level (i.e. flood depth or inundation velocity). For instance, the HAZUS multi-hazard framework (Scawthorn et al. 2006a, b) collects a rich database of predefined vulnerability curves for the main components of built environment (i.e. building, street, bridges, etc.). In the recent years, flood-induced damage to buildings has attracted increasing attention (Smith 1994; Schwarz and Maiwald 2008; Nadal et al. 2010; De Risi et al. 2013b). De Risi et al. (2013a) demonstrated how to calculate the risk for a portfolio of informal buildings in a flood-prone area in Dar Es Salaam, Tanzania. Moreover, the authors have demonstrated how to calculate the flooding fragility analytically for a single 
non-engineered building (Jalayer et al. 2016). Jalayer et al. (2018) have also demonstrated how to evaluate analytically the damage due to flash flood and debris flow for an older masonry building in Messina, Sicily region, Italy. Finally, Jalayer et al. (2014) proposed a methodology for identifying the flooding risk hotspots in which the UMTs were used as a proxy for representing the building vulnerability. The methodology can be further developed by considering the spatial variation of building flood vulnerability within residential UMT spatial units in a bottom-up approach that uses the microscale results in the mesoscale (city level) maps. This constitutes a starting point for a probabilistic methodology aiming at prediction of flooding risk for a portfolio of structures and leads to mesoscale flood risk maps in GIS environment that are especially suitable for strategic and adaptive urban planning.

Building upon the previous literature, with specific reference to strategic urban decision-making, this work presents a fast screening/visualization method for flood risk zoning, referred to as Demand over Capacity ratio map, that distinguishes in binary terms (safe and unsafe) between areas in which the risk is below a tolerable threshold and areas in which it is not (and therefore actions are needed to be programmed). The proposed methodology is applied to the city of Addis Ababa (Ethiopia), which is one of the case study cities studied in the context of the Seventh Framework European project Climate Change and Urban Vulnerability in Africa (CLUVA, Herslund et al. 2016). Moreover, in this area, heavy rains and flooding have led to loss of life and have left thousands of people without a home in August 2006 (DRMFS 2006).

\section{Methodology}

The flood risk maps are obtained herein by direct integration of hazard, vulnerability and exposure. This implies that the hazard maps and vulnerability calculations are by-products of this process. In addition, an innovative fast visualizing/screening tool, namely the "Flood Risk Zoning: Demand over Capacity ratio map," is developed. The methodology proposed in this work can be summarized in a step-by-step manner:

1. Preliminary screening for the identification of the flooding risk hotspots (following the procedure proposed in Jalayer et al. 2014) in residential areas; this step leads to the identification of the buildings that are potentially at risk;

2. Collection of detailed information about the identified flooding risk hotspots, such as the characteristics of the built environment (e.g., buildings' footprints, number of storeys, time of construction) and detailed exposure characteristics (e.g., functionality, population density);

3. Computation of inundation maps for different return periods for the delineated flooding risk hotspots by carrying out a detailed hydrologic-hydraulic routine (e.g., the routine outlined in De Risi et al. 2013a);

4. Gathering of additional information to identify the different building types within the UMTs (those related to the built environment; however, the procedure is applicable also to other UMTs).

5. Analysis of the vulnerability of the portfolio of structures of interest (following the procedure outlined in De Risi et al. 2013a; Jalayer et al. 2016) to build analytical fragility curves for each building type;

6. Generation of Risk and Demand over Capacity ratio maps. 
In the following, an overview of the different phases is illustrated.

\subsection{The probabilistic basis for risk evaluation}

The structural vulnerability herein refers to the effects of the natural phenomena on the physical integrity of the structure. As such, it quantifies the structure's potential of losing a specific functionality. In such a context, fragility curves provide a visual and efficient way of representing the structural vulnerability. The structural fragility usually refers to a specific structural limit state (Porter et al. 2007). Formally, the flooding fragility can be defined as the probability of exceeding a specific limit state given a specific value of flood intensity measure. The flood hazard represents the frequency and the intensity of the flooding event. It is defined as the mean annual rate that a certain flood intensity measure is exceeded. The flooding risk can be represented by adopting alternative risk metrics. One viable risk metric is the annual frequency of exceeding a prescribed limit state denoted as $\lambda_{\mathrm{LS}}$. This risk metric is obtained through direct integration of fragility and hazard, adopting the flood height $h_{\mathrm{f}}$ as an interface variable (a.k.a., flood intensity measure):

$$
\lambda_{\mathrm{LS}}=\int_{h_{\mathrm{f}}} P\left(\mathrm{LS} \mid h_{\mathrm{f}}\right) \cdot\left|\mathrm{d} \lambda\left(h_{\mathrm{f}}\right)\right|
$$

where $\lambda\left(h_{\mathrm{f}}\right)$ denotes the mean annual rate of exceedance of a given flooding height $h_{\mathrm{f}}$ at a given point in the considered area. $P\left(\mathrm{LS} \mid h_{\mathrm{f}}\right)$ denotes the flooding fragility for limit state LS expressed in terms of the probability of exceeding the limit state threshold. The integration of the fragility $P\left(\operatorname{LS} \mid h_{\mathrm{f}}\right)$ and the (absolute value of) hazard increment $\operatorname{ld} \lambda\left(h_{\mathrm{f}}\right) \mid$ is carried out over all possible values of flooding height. Assuming that the limit state excursion is expressed by a homogenous Poisson recurrence process, the probability of exceeding the limit state (at least once) in a specified time interval $t$ denoted as P(LS; $t$ ) is calculated as:

$$
P(\mathrm{LS} ; t)=1-\exp \left(-\lambda_{\mathrm{LS}} \cdot t\right)
$$

For $t=1$ year, the $\mathrm{P}(\mathrm{LS} ; t)$ can be simply expressed as the annual probability of limit state exceedance and denoted as $\mathrm{P}(L S)$.

An alternative metric for risk is expressed as the expected value of number of people in the residential areas potentially exposed to flooding risk. This metric is calculated based on specific exposure data $R$, for example, the population density datasets. More in detail, the expected number of people potentially exposed to flooding risk in a year (per building or per unit residential area) $E[R]$ can be calculated as:

$$
E[R]=P(C) \cdot R
$$

where $P(C)$ is the annual probability of collapse (the probability of exceeding the collapse limit state at least once in one year) and $R$ is the number of people occupying the building or the areal extent in question. Substituting $R$ with the replacement cost, the expected replacement cost, that quantifies the risk in financial terms, is obtained.

\subsubsection{Evaluation of inundation maps}

The inundation profile refers to the map of flooding heights (and velocities) for various nodes within a lattice covering a given area for different return periods. It can be calculated by means of classic hydraulic routines of various degrees of sophistication 
and accuracy (Apel et al. 2009). The calculation of the inundation profile is carried out herein through the step-by-step procedure reported below (described in more detail in De Risi et al. 2013a):

1. Definition of the rainfall intensity-duration-frequency (IDF) curves based on historic rainfall annual maxima (De Paola et al. 2014). These curves provide the frequency (or the return period) of exceeding various rainfall scenarios characterized by the rainfall intensity (average rainfall depth in $\mathrm{mm}$ per time increment) measured in a given time window (duration).

2. Gathering spatial datasets such as the digital elevation model (DEM), digital surface model (DSM), the geology map, and a representation of land use/land cover for the zone(s) of interest.

3. Calculation of the hydrographs for the various return periods associated with the rainfall curves. The hydrograph refers to the flow discharge as a function of time and constitutes the input for the hydraulic diffusion model. A detailed description of the methodology is explained in "Appendix A."

4. Diffusion of the total discharge volume (area under the hydrograph) based on the general constitutive equations of continuity and fluid dynamics (i.e. one-dimensional or bi-dimensional diffusion models). This can be done by means of various software tools (e.g., FLO2D 2004; HEC-RAS 2010, etc.).

The two-dimensional flood routing for a given surface grid in the flood-prone area provides the values of water height and velocity for a given return period. These results can be visualized as the flood height/velocity maps for a range of return periods. Alternatively, it is possible to represent the results in terms of the flood hazard curves depicting the mean annual rate of exceeding various flood heights/velocities for each grid point within the zone. The hazard curves for flood height show the mean annual frequency $\lambda\left(h_{\mathrm{f}}\right)$ (see Eq. 1) of exceeding a specific flood height $h_{\mathrm{f}}$.

\subsubsection{Fragility evaluation for a class of structures}

The procedure employed in this work for the assessment of the vulnerability of buildings is described in detail in Jalayer et al. (2016) and is suitable for a mono-class portfolio of buildings; that is a group of buildings belonging to the same class. A class can be defined based on a prescribed set of characteristics (for example, construction material, number of stories, time of construction or a combination of these features). As far as it regards the application presented in this work, the settlements located in the same neighborhood and grouped under the same UMT classification, tend to have similar characteristics. For instance, they usually have the same number of floors, the same wall material (e.g., adobe, rammed earth or cement-stabilized blocks), the same roof material (e.g., corrugated iron sheet or wooden frame) and similar geometrical features. Since UMT maps are obtained based on automatic supervised algorithm working on highresolution orthophotographs, the characteristics of the buildings within a UMT class are expected to be uniform; therefore, the UMT's buildings can be characterized as a single class of buildings. In the following, the vulnerability assessment procedure is outlined in a step-by-step manner for a prescribed building class and a prescribed limit state (see De Risi et al. 2013b for more details): 
1. Data acquisition: in this step, various data acquisition techniques (remote sensing, orthophotographs, boundary recognition, filed survey and available literature) are combined in order to gather sufficient information for calculating the vulnerability of the structural classes.

2. Simulation: for each building class, a limited number of buildings are generated using simulation. The buildings are generated to represent both the building-to-building variability within each class and the uncertainty in characterizing the structural modeling parameters for a single building. For evaluating the portfolio vulnerability, the buildingto-building variability is expected to be predominant. The field surveys lead to statistics that strive to emulate both the building-to-building variability and the structural modeling uncertainties. Nevertheless, such statistics are arguably more suitable for estimating the building-to-building variability within a certain building class (see De Risi et al. 2013a, b for more information).

3. Structural analysis: In this step, each of the buildings generated in the previous step is studied by means of structural analysis (see Jalayer et al. 2016 for more detail). It is worth noting that, given the limited number of structures to be analyzed, a relatively high level of analysis detail can be chosen.

4. Fragility assessment: In this step, the structural analysis results, expressed for instance as the critical flood heights for a given limit state, are transformed into fragility curves. Herein, the Robust Fragility method (Jalayer et al. 2013b, 2016) is used to extract fragility curves and their plus/minus one standard deviation confidence interval (reflecting the uncertainty in evaluating the fragility model parameters based on a limited sample of structural analysis data).

The fragility curves derived herein correspond to the Collapse limit state (CO) and are calculated as the cumulative distribution (CDF) for critical flooding height $\left(h_{\mathrm{f}, \mathrm{c}}\right)$ for which the most vulnerable section of the most vulnerable wall in the building is going to exceed the stress capacity (Jalayer et al. 2016). The critical water height for the Collapse limit state is calculated (by employing structural analysis) considering the various sources of uncertainties in geometry, material properties and construction details (as mentioned above, reflecting both building-to-building variability and the structural modeling uncertainties).

\subsection{Fast flood risk zoning employing demand over capacity ratio map}

The risk maps are represented in terms of probabilities (or alternatively rates) of exceeding a prescribed limit state. However, the transformation of risk values (probabilities) to decisions is certainly not trivial and requires the definition of acceptable risk thresholds for limit states of interest. In lieu of specific decision-making protocols which can help in carrying out the mapping from risk to decisions, it is particularly helpful to represent the risk maps in a more tangible manner. For instance, the risk maps can also be represented in terms of the margin of safety with respect to a prescribed limit state. The demand to capacity safety ratio (SR) for a given limit state (herein, Collapse) denoted as $\mathrm{SR}_{\mathrm{LS}}$ (Jalayer 2018) in its turn can be transformed into a binary variable, where 0 represents safe (demand to capacity ratio less than or equal to unity) and 1 represents unsafe (demand to capacity ratio greater than unity). This provides clear-cut information in support of decision-making.

Herein, the demand to capacity safety ratio $\mathrm{SR}_{\mathrm{LS}}$ is calculated through a simplified analytic and closed-form probabilistic safety-checking procedure proposed by Cornell et al. 
(2002) for seismic hazard and later adapted for flood safety checking in Jalayer et al. (2016):

$$
\mathrm{SR}_{\mathrm{LS}}=\frac{\mathrm{FD}}{\mathrm{FC}}=\frac{h_{\mathrm{F}}\left(\lambda_{\mathrm{o}}\right)}{\eta_{h_{\mathrm{cr}}(L S)} \cdot \exp \left(-\frac{1}{2} k \beta_{h_{\mathrm{cr}}(\mathrm{LS})}^{2}\right)}
$$

where FD is the factored demand (i.e., demand magnified to reflect uncertainties); FC is the factored capacity (i.e., capacity de-magnified to reflect uncertainties); $\lambda_{\mathrm{o}}$ is the acceptable rate of exceedance calculated as a function of the acceptable probability $P_{\mathrm{o}}$ for limit state LS in $t$ years ( $t$ being the service life time of the building; e.g., 10\% in 30 years for the collapse limit state) from Eq. $2 ; h_{\mathrm{f}}$ is the flooding height value corresponding to $P_{\mathrm{o}}$ probability of being exceeded in service life $t$ from the hazard curve; $\eta_{\mathrm{hcr}(\mathrm{LS})}$ is the median critical flood height for the prescribed limit state LS; $k$ is the slope of the hazard curve in the logarithmic scale evaluated at the median critical height value $\eta_{\text {hcr(LS) }}$ (Jalayer 2018); and $\beta_{\text {hcr(LS) }}$ is the standard deviation of the natural logarithm of the critical flooding height for the prescribed limit state.

\subsection{Flood risk mitigation strategies}

The flood risk maps can be used as a support for decision-making between alternative flood mitigation strategies. In the literature, the flood risk mitigation strategies are classified into structural and non-structural (Thampapillai and Musgrave 1985). The structural measures consist in envisioning physical constructions and techniques that aim at reducing the flooding hazard. The structural mitigation strategies usually modify the streamflow of rivers and channels leading to the reduction in the frequency and intensity of floods. For example, reservoirs reduce peak flows; levees and flood walls confine the flow within predetermined channels; improvements to channels such as debris removal or riverbed maintenance reduce the peak stages; the floodways help in diverting excessive flow. Given the large variety of structural measures, a further subdivision is needed; in fact, the structural measures are also divided into active and passive measures.

The active structural measures modify the hydrograph by reducing and delaying the maximum peak discharge. Floodplain storage (on- and off-stream) is an example of active structural measure; it temporarily stores the flood volume in an adequate upstream capacity and attenuates the flooding by slowing down the discharge release (Topa et al. 2014). As soon as the discharge falls below the maximum allowable level, the flood volume is released back to the river (De Martino et al. 2012). The on-stream floodplain storages are preferred over the off-stream ones; since they do not interfere with the natural drainage pattern established between the stream and the floodplain. In the case of off-stream storage, an outlet structure needs to be envisioned to regulate the outflow discharge.

The passive structural measures mitigate flooding by adjusting the riverbed; this leads to channel improvement without modifying the hydrograph. Examples are installation of levees, increasing the riverbed section (e.g., by cleaning from debris), and installation of hydraulic bypass (a.k.a., waterways).

The non-structural measures, as the name implies, are procedures that do not involve the installation of physical constructions. These measures consist of actions that lead to promoting knowledge, enforcing best practices, raising awareness and implementing strategic policies (Kundzewicz 2002). For example, flood early warning systems are an example of flood mitigation best practice that aims at providing a minimum amount of time for the 
residents to evacuate the area in case of eminent flooding. Land use regulations are examples of strategic policy-making that help in delineating areas where urban development can be planned and in identifying the lowest habitable floor in flood-prone residential areas. Flood insurance and planned relocation can also be classified as strategic policy-making for flood risk mitigation. Measures such as strengthening the structure against the flood actions and raising the elevation of buildings (and thus eliminating the flood actions) can be classified among best practices for flood-resistant upgrading of building.

In this work, both structural and non-structural flood risk mitigation measures have been considered. The (hypothetic) installation of an on-stream flood plain storage and proposal of simple upgrade measures for the buildings are examples of active structural and nonstructural mitigation strategies discussed hereafter.

\section{The case of Addis Ababa}

In the following, the methodology described earlier is implemented to produce flooding risk maps for residential buildings located in the central part of the city of Addis Ababa (for brevity referred to also as Addis), Ethiopia. Addis is the capital and the largest city in Ethiopia, with a population of about 2,800,000, according to the 2007 population census. The city is situated on the high plateau of central Ethiopia which is aligned with the North-South-oriented mountain systems neighboring the Rift-Valley. The city is overlooked by Mount Yarer in the east, Mount Entoto in the north and Mount Wochecha in the west. Several small streams originate in the mountains surrounding the city and flow into the metropolitan area of Addis Ababa. Torrential rains, which are common during the rainy season, cause a sudden rise in the flow of these streams and periodically inundate the settlements built along their banks. The flooding of August 2006 was the worst in Ethiopian history. It affected 363,000 people and left approximately 200,000 people homeless (DRMFS 2006). The final death toll was estimated at around 647 but the impacts on health and well-being were much larger.

\subsection{Description of the case study area}

In a previous work (Jalayer et al. 2014), the authors have proposed a probabilistic GISbased method for delineating the flood risk hotspots adopting Addis Ababa as the case study. The number of people potentially affected by flooding, estimated through this probabilistic procedure, is shown in Fig. 1a. It emerges that one of the critically affected areas due to flooding is in the city center, between the sub-cities of Bole, Kirkos and Yeka. Therefore, this area requires more refined flood risk assessment studies. The area is crossed by the Bulbula river. The catchment of Bulbula river is composed by the intersection of two catchment areas attributed to two secondary streams, identified as B1 and B2, depicted in Fig. $1 \mathrm{~b}$ and delineated with green and yellow lines, respectively. The main morphometric proprieties of these two catchments are reported in Table 1.

\subsubsection{Geology}

A large part of the basin is composed of volcanic rocks, as depicted in Fig. 2a. The northern and eastern sides of the basin consist of layers of mixed rock. The western side of the 

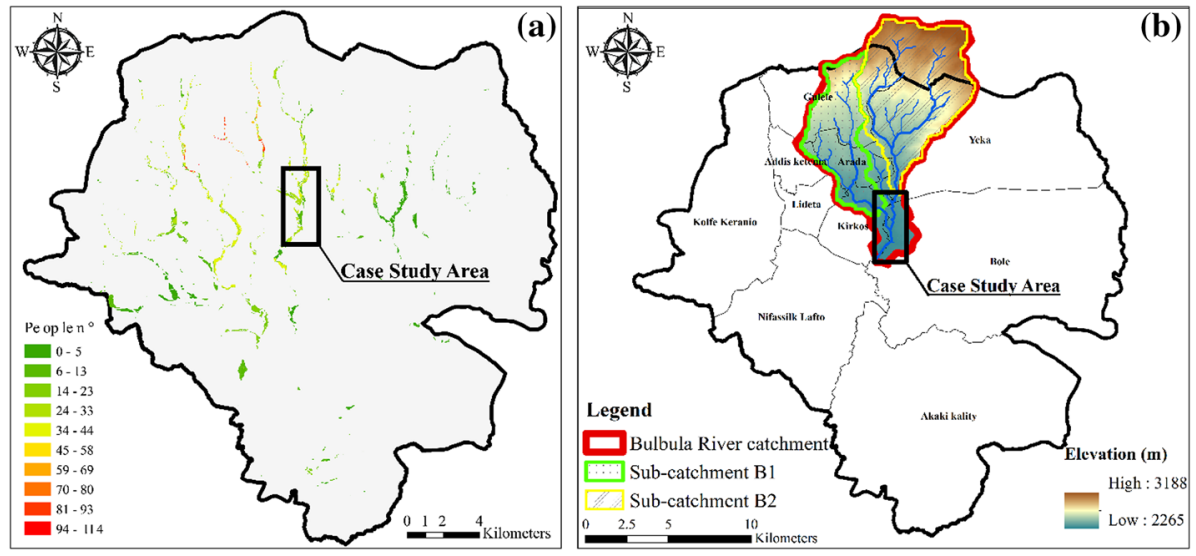

Fig. 1 a Flooding risk hotspots: the map of number of people potentially at risk, b Orography of the case study area and catchments of the Bulbula river (vertical resolution $1 \mathrm{~m}$ )

Table 1 Main morphometric properties of the catchments B1 and $\mathrm{B} 2$

\begin{tabular}{lll}
\hline & B1 & B2 \\
\hline Catchment area $\left(\mathrm{km}^{2}\right)$ & 24.1 & 46.2 \\
Max elevation (m) & 3010 & 3179 \\
Min elevation (m) & 2332 & 2365 \\
Average elevation (m) & 2538 & 2752 \\
Average slope basin (\%) & 10.47 & 15.54 \\
Stream length (m) & 11,089 & 12,812 \\
Max flow length (m) & 11,663 & 13,885 \\
CN (-) & 70.67 & 66.16 \\
$T_{\mathrm{C}}$ (NRCS 1997) (h) & 4.0 & 4.2 \\
\hline
\end{tabular}

(a)

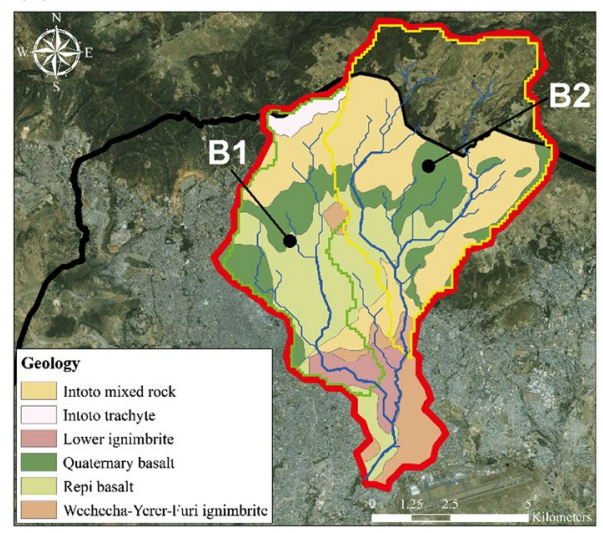

(b)

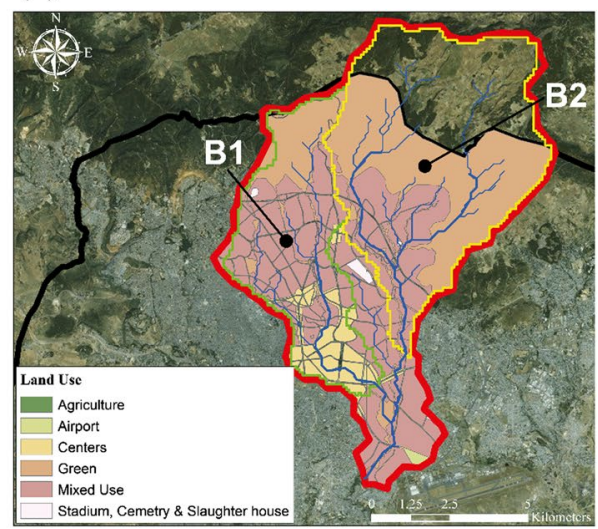

Fig. 2 a Geology and b land use for the case study catchment. (Horizontal resolution $300 \mathrm{~m}$ ) 
basin is mainly made up of basaltic rocks. Along the river, rock formations consist of ignimbrite, whereas in the southern part some pockets of basalt formations can be found.

\subsubsection{Land use}

Land use identification is very important both for the detection of the precipitation retention capacity and the channeling of the water flow. The high-elevation portion of the catchment is mainly characterized by vegetation. The lower part of the catchments falls in a densely urbanized area. Figure $2 b$ depicts different land use types for the case study catchment.

\subsection{Hydrologic and 2D hydraulic modeling}

\subsubsection{The meteorological features}

Addis Ababa has a subtropical highland climate. It falls into "the temperate climate with dry winters (Cwb)" category, according to Köppen climate classification, with dry winters and rainy summers (Kottek et al. 2006). The precipitation data in ( $\mathrm{mm}$ ) and average rainfall days (days) for the time-period 2000-2012 are shown in Fig. 3. These data have been used to obtain the hydrograph for the two basins B1 and B2 of the case study (Fig. 4).

\subsubsection{The characterization of the hydrographs}

The peak flow for the two catchments is evaluated by employing the Curve Number method for six return periods (e.g., 2, 10, 30, 50, 100, and 300 years). The inflow hydrographs for catchment B2 and B1 corresponding to the various return periods considered are illustrated in Fig. 5a, b, respectively.

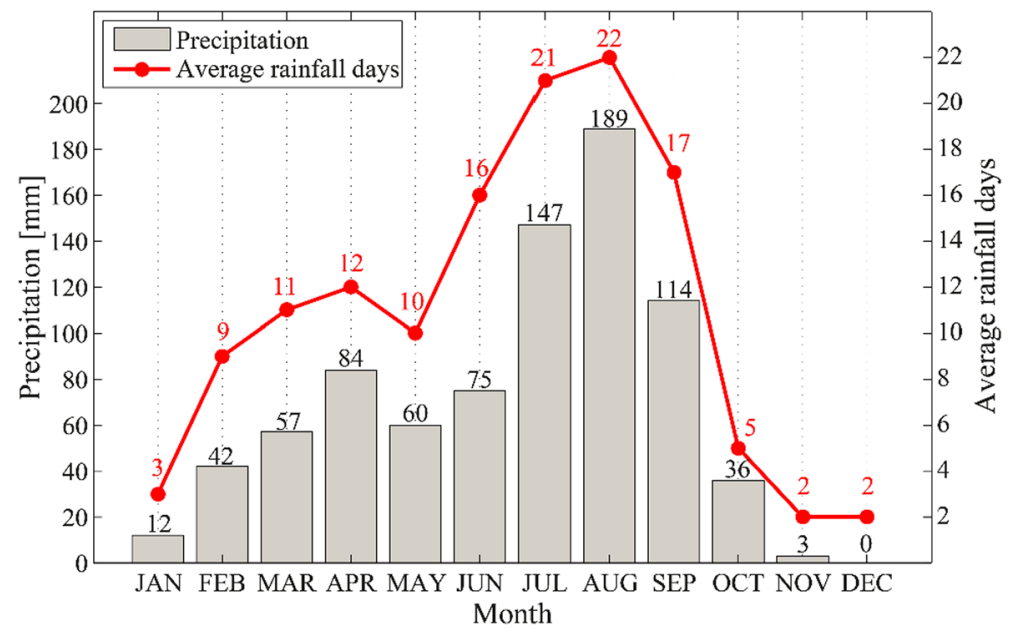

Fig. 3 Precipitation and average rainfall days in Addis Ababa between 2000 and 2012 

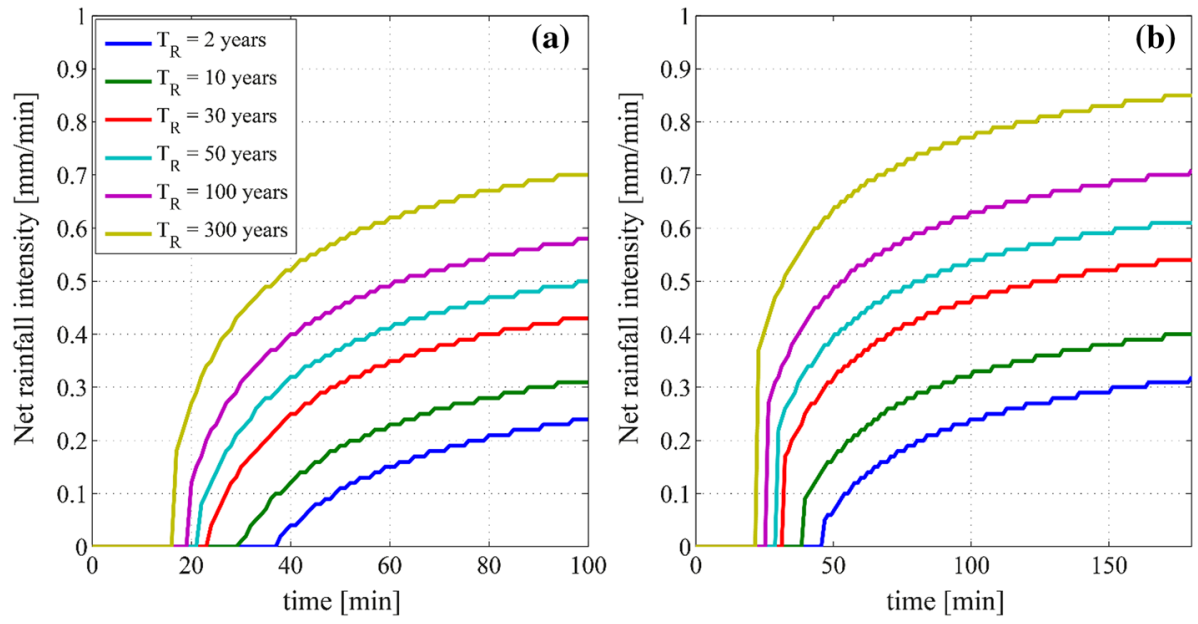

Fig. 4 Hydrograph related to a catchment B1 and b catchment B2
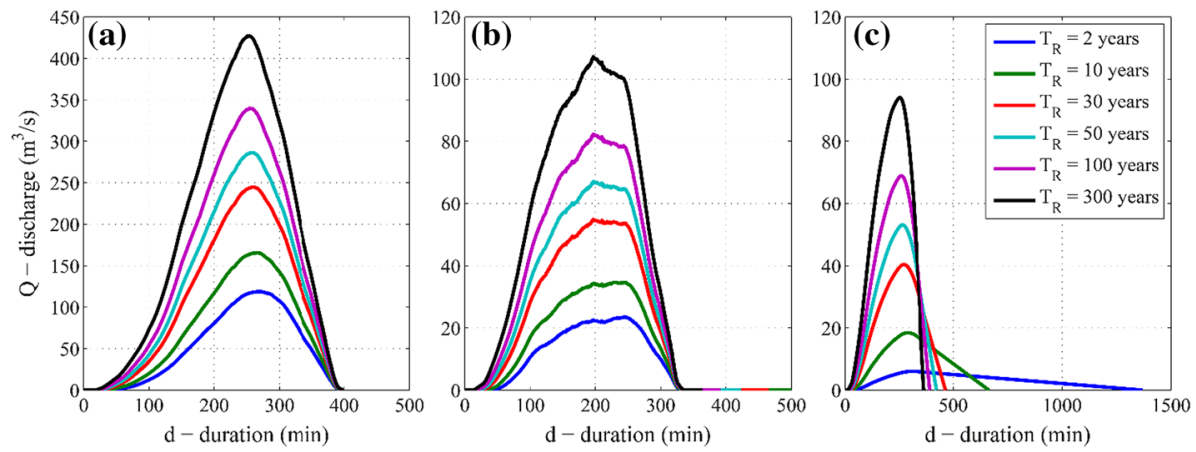

Fig. 5 Hydrographs: a catchment B2, b catchment B1 without floodplain storage, c catchment B1 with floodplain storage. Note that figure $\mathbf{c}$ has an extended time axis to demonstrate the effect of the flood storage

\subsubsection{The impact of the floodplain storage mitigations}

As a viable structural flood risk mitigation strategy, the possibility of realizing an onstream floodplain storage with a maximum capacity of about 190,000 $\mathrm{m}^{3}$ (a flood plain surface of $38,000 \mathrm{~m}^{2}$, with a maximum flood depth inside the floodplain equal to $5 \mathrm{~m}$ ) along the stream line of the sub catchment B1 has been evaluated. The procedure for designing the flood plain storage is outlined in "Appendix B." Figure $5 \mathrm{c}$ demonstrates the effect in terms of the reduction of the hydrograph peak and increased duration, especially for the lower return periods.

\subsubsection{The flood hazards}

The software FLO-2D (O'Brien et al. 1993; FLO-2D 2004) has been used herein for a two-dimensional simulation of the propagation of the flooding volume based on the calculated hydrographs and a digital elevation model (DEM) assuming a $10 \mathrm{~h}$ simulation time. 

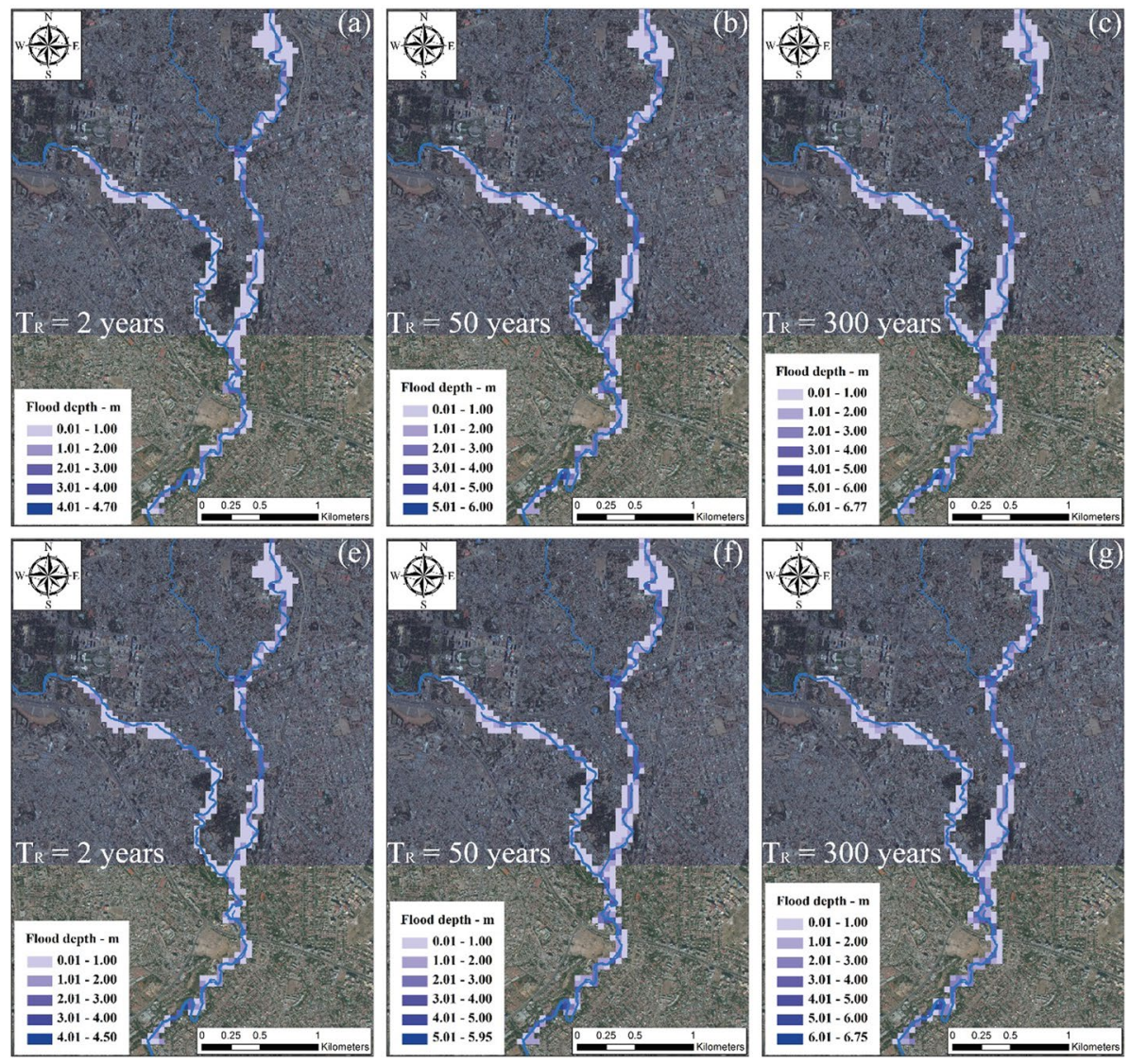

Fig. 6 Inundation profiles for different return periods in terms of $h_{\text {max }}$ : a $T_{\mathrm{R}}=2$ years without floodplain storage, b $T_{\mathrm{R}}=50$ years without floodplain storage, $\mathbf{c} T_{\mathrm{R}}=300$ years without floodplain storage, d $T_{\mathrm{R}}=2$ years with floodplain storage, e $T_{\mathrm{R}}=50$ years with floodplain storage, $\mathbf{f} T_{\mathrm{R}}=300$ years with floodplain storage

FLO-2D is widely used commercial software for flood propagation simulation and has been validated by the US Federal Agency (FEMA). The outcome of the flood propagation is illustrated in Fig. 6, in terms of maximum flow depth (in meters), for three return periods (2, 50 and 300 years) with and without floodplain storage. The on-stream floodplain storage is assumed to be empty at the beginning of the simulation. The simulation time step is set to $1 \mathrm{~min}$. Figure 6 shows that the application of a floodplain storage leads to a small reduction (less than $10 \%$ ) of the inundation maximum intensity in the northwest streamline and in the south part after the confluence of the two rivers. The application of this structural mitigation measure leads to slight reduction in flooding extent in catchment B1 since in densely urbanized areas it is very difficult to find the available land that is necessary to build the floodplain storage. 

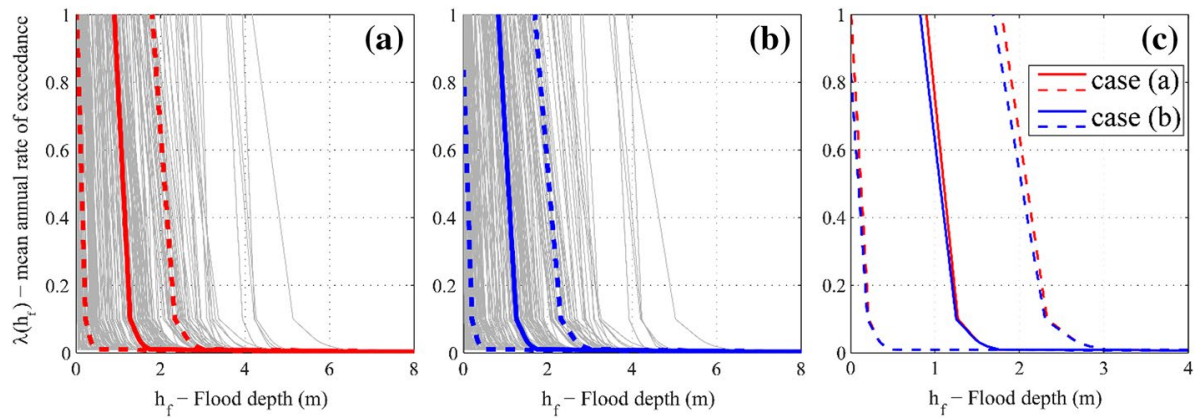

Fig. 7 Flood hazard curves in terms of maximum flood height: a without floodplain storage, b with flood plain storage, c comparison between the two cases

\subsubsection{The flood hazards curves}

The flood hazard curves, that demonstrate the mean annual rate of exceeding various flooding depths (i.e. inverse of the return period) versus flood depth for various pixels within the flooding plain mesh, are shown in Fig. 7. The hazard curves plotted in light gray are for those pixels that mark the centroid of a building belonging to the portfolio of the buildings subjected to inundation. The hazard curves plotted in thick continuous and dashed lines represent the mean, and the mean plus/minus one standard deviation curves, respectively. Figure $7 \mathrm{a}, \mathrm{b}$ show the flood hazard curves without and with floodplain storage, respectively. Figure 7c shows the comparison between the two cases. A very slight reduction in the flood depth can be observed in case the flood storage is envisioned (blue lines) with respect to the case when it is not (the red lines) for small return periods.

(a)

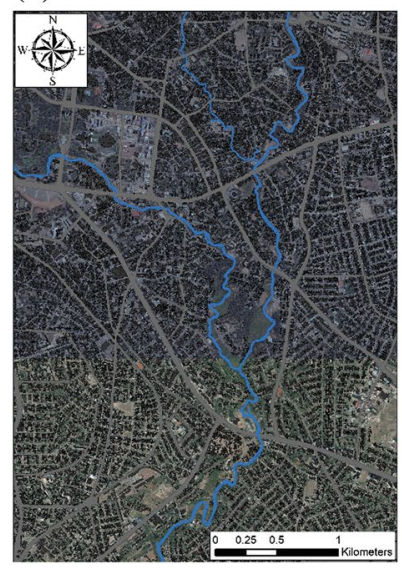

(b)

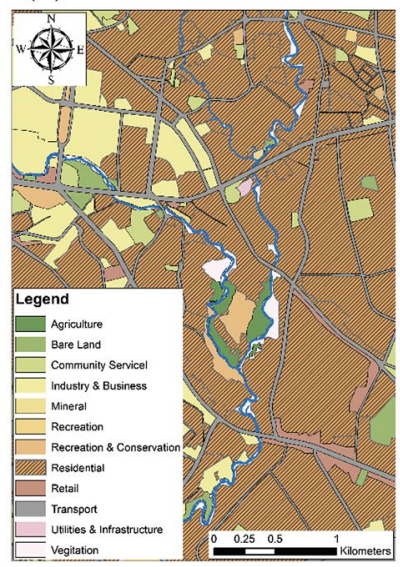

(c)

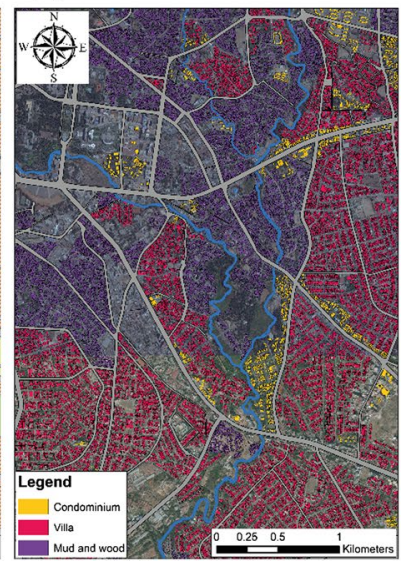

Fig. 8 Identification of exposure: a buildings' footprints, b UMT map for the case study area (Resolution 1:2000), $\mathbf{c}$ buildings in residential area classified according to the structural typology 


\subsection{Identification of the exposure}

Based on the map produced by Addis Ababa municipality representing the buildings' footprints for the entire city, there are about 83,500 buildings located in the case study area (Fig. 8a). According to the UMT map (Cavan et al. 2012), about the of the entire area is characterized as residential (i.e. the area with inclined line pattern colored in brown in Fig. 8 b). The number of buildings in the residential area has been estimated by overlaying the buildings' footprint and the residential UMT map. According to the UMT classification, three different types of buildings have been identified; namely, Condominium, Villa and Mud and Wood structures, represented with orange, magenta and purple colors, respectively. Condominium, Villa, and Mud and Wood represent 5\%, 49\% and 46\% of the entire residential building portfolio, respectively. Figure 9 shows the three types of structures identified. Based on the statistics obtained by the Addis Ababa municipality, the average population density in this residential area is equal to 4 people per household.

\subsection{Structural vulnerability and mitigation strategies}

Condominium buildings (Fig. 9a) are multistory reinforced concrete frames with hollowed cement block infills. The external facades are generally finished with mortar and plaster to make them more waterproof. Villas (Fig. 9b) are single-story regular masonry buildings. They are made of hollowed cement blocks, with the mortar layers between the blocks often missing. The walls generally lack the waterproof plaster finish. The thickness of the wall is generally equal to the thickness of the cement block (variable between 100 and $200 \mathrm{~mm}$ ) plus the plaster thickness (variable between 10 and $20 \mathrm{~mm}$ ) if present. Mud and Wood structures (Fig. 9c) are single-story buildings. The walls are composed of a series
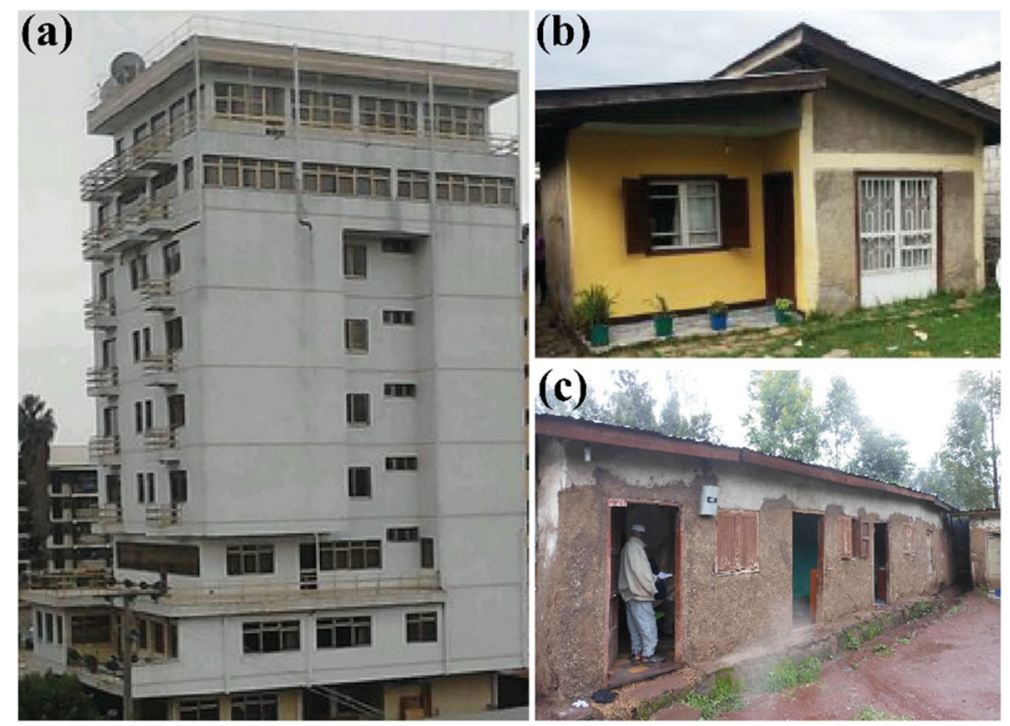

Fig. 9 Typical buildings in Addis Ababa identified as: a Condominium, b Villa, c Mud and Wood 
of poles, having different diameter size, placed side by side. The presence of a transversal support for poles does not seem to be guaranteed. Whenever it is present, the transverse support consists of one or two poles horizontally placed often in an irregular manner. Nevertheless, the presence of a sufficient connection between the horizontal support elements and the vertical elements is not guaranteed. The wooden poles are covered by a mud layer mixed with straw that is especially useful for thermal insulation. In cases where the mud is not protected with a water-tight plaster layer, the mud risks being washed away by flooding. This composite building material (mud and wood) is also known as "wattle and daub" (Fleisher and LaViolette 1999).

Applying the procedure explained at point 2.1.2, the collapse fragility curves for the three types of structures identified have been obtained (Fig. 10, see Carozza et al. 2013 for more detail). In the following section, the attention is focused on vulnerability reduction measures for Villa and Mud and Wood structures. Given that only a small percentage of Condominium buildings falls in the case study area and that they are constructed based on engineering standards, the vulnerability reduction measures for these buildings are not discussed herein.

\subsubsection{Flood vulnerability mitigation for mud and wood and cement block structures}

A very efficient technique for protecting the building against flooding is to raise the foundation above the ground level. The raised foundation can be constructed by adopting different techniques: (a) using cement-stabilized earth and stone; (b) using brick perimeter walls with a core made up of an earth and cement mix; (c) using stilt foundations; (d) using wooden pallets.

As a matter of fact, the first strategy proposed herein for flood vulnerability reduction is to raise the foundation above the ground level by $40 \mathrm{~cm}$ using cement-stabilized earth and stone. This solution has been chosen because of its applicability to existing structures and due to the fact that it is not too invasive from an architectonical point of view (although it leads to a reduction of around $40 \mathrm{~cm}$ in the floor-to-ceiling clear height).

The second solution proposed in this paper is applying a dry protection strategy consisting in the application of a waterproofing plaster to the exterior walls. This solution is not

Fig. 10 Fragility curves for the three typologies of structures

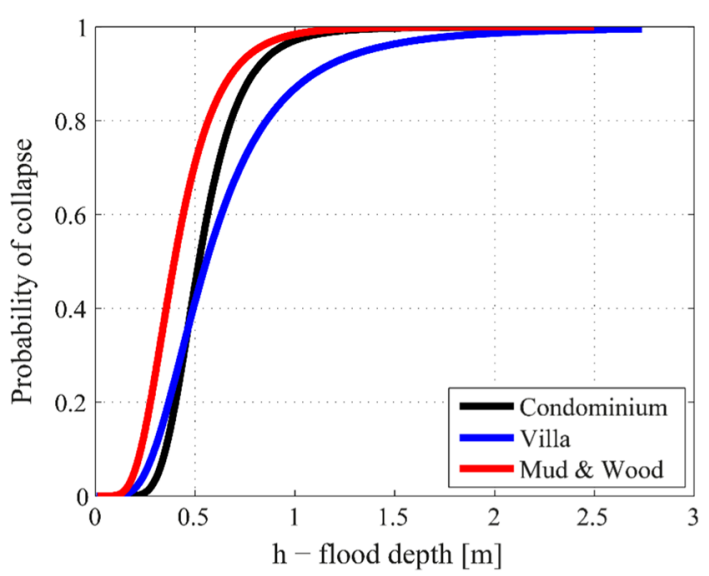


(a)

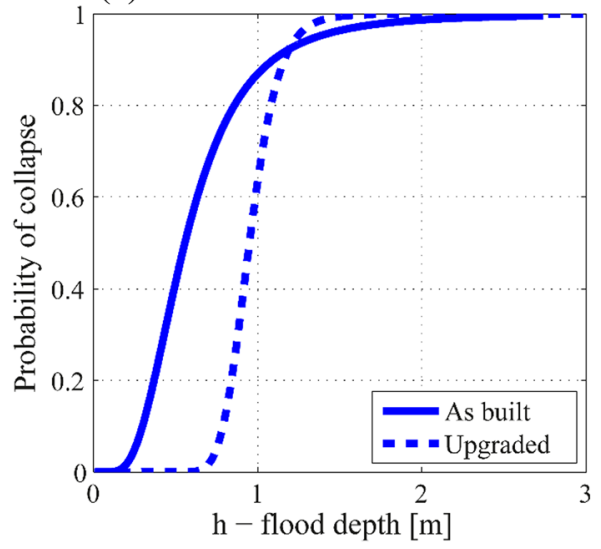

(b)

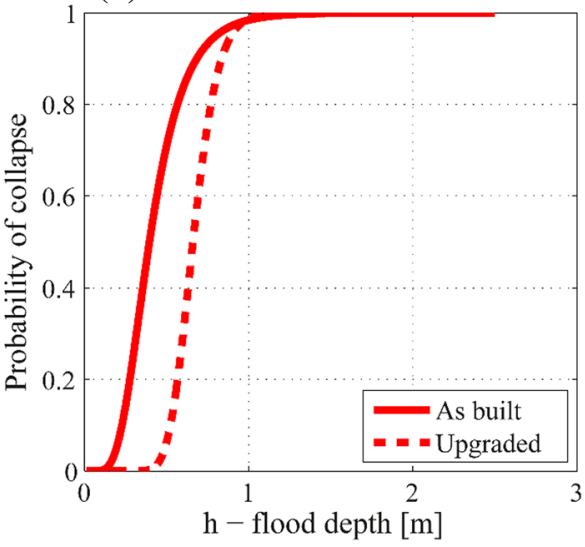

Fig. 11 Fragility curves corresponding to as-built and upgraded (waterproof + raised foundation) configuration for: a Villa; and b Mud and Wood structures

only useful in avoiding direct contact of the construction materials with water (it avoids the potential degradation of the material) but also it may increase the mechanical material properties. Carozza et al. (2015) shows how this typology of retrofitting strategy is modeled and improves the overall strength.

Figure $11 \mathrm{a}, \mathrm{b}$ depicts with dotted lines the fragility curves obtained based on the (hypothetic) application of the above-mentioned mitigation measures (raised foundation and applying a waterproof plaster) to the two classes (i.e., Villas and Mud and Wood). It can be observed that the proposed mitigation strategies lead to an increase of about $100 \%$ in the median and a slight reduction in the dispersion.

\subsection{Flood risk maps}

According to the proposed procedure, the first step in flood risk mapping is overlaying of the flood hazard maps, the building footprints and the UMT map (identifying the structural class). This leads to the identification of flooding risk hotspots in the case study area and the number of buildings at risk. As a result, the maximum number of people exposed to flooding risk can be estimated by multiplying the number of buildings whose footprints fall within the delineated hotspots (i.e., the buildings at risk) and the average number of occupants/building (estimated based on the available population density spatial datasets). In the next step, the expected number of people at risk is then calculated according to Eq. 3.

Figure 12 illustrates the expected value of number of people affected by flooding per household in one year (without the floodplain storage) calculated from Eq. 3 (a) for the as-built configuration (without structural upgrading); and (b) after the (hypothetic) application of structural upgrading measures. The results are obtained by integrating the fragility curves reported in Figs. 10 and 11 with the hazard curves for the initial configuration (i.e., without floodplain storage) reported in Fig. 7a. It can be observed that structural upgrading results in a reduction of people at risk especially in the northern part of the case study area (compare sub-windows a1-b1, a2-b2 and a3-b3 in Fig. 12).

Table 2 reports the expected value of people at risk per year in the entire case study area; the actual configuration is assumed as the reference case. There is no difference in 
(a)

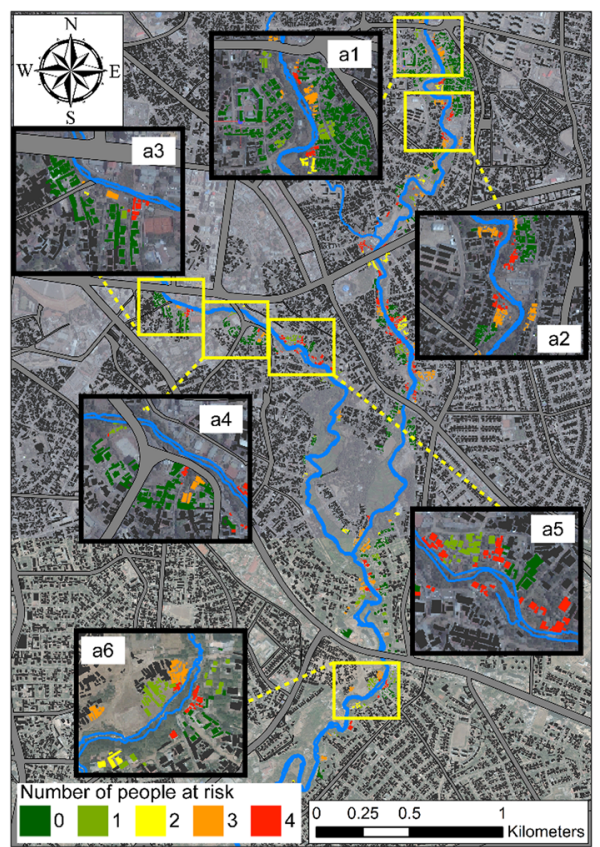

(b)

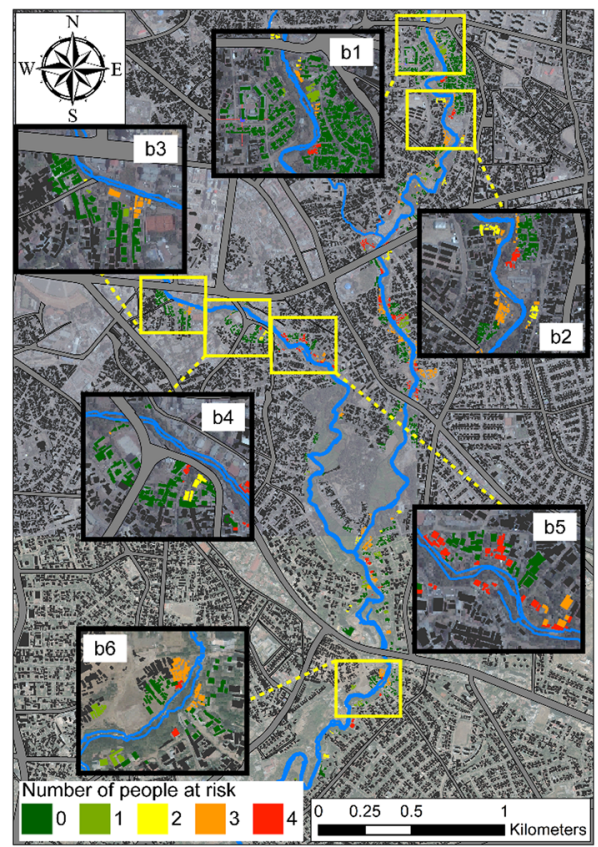

Fig. 12 Number of people at risk per each building considering a actual configuration of buildings and b upgrading of structures

Table 2 Risk expressed in terms of expected number of people at risk per year

\begin{tabular}{|c|c|c|c|}
\hline Building typology & Buildings at risk & $\begin{array}{l}\text { Maximum number of } \\
\text { people at risk }\end{array}$ & $\begin{array}{l}\text { Expected number of } \\
\text { people at risk per year } \\
\text { (Eq. 3) }\end{array}$ \\
\hline \multicolumn{4}{|c|}{ Actual configuration (reference case) } \\
\hline Condominium & 283 & 1132 & 206 \\
\hline Villa & 465 & 1860 & 551 \\
\hline Mud and Wood & 1840 & 7360 & 2564 \\
\hline \multicolumn{4}{|c|}{ After structural upgrading, w/o floodplain storage } \\
\hline Condominium & 283 & 1132 & 206 \\
\hline Villa & 465 & 1860 & 340 \\
\hline Mud and Wood & 1840 & 7360 & 2003 \\
\hline
\end{tabular}

the number of buildings at risk and therefore in the maximum number of people at risk between the two reported cases. This is because the hazard maps are the same in both cases (the floodplain storage is not considered) and the structural fragility is not considered for estimating the maximum number of people at risk. Moreover, the expected value of people at risk for Condominium remains invariant for the two cases since no upgrading strategies were considered for this typology of buildings.

On the other hand, applying structural upgrading strategies to the other two (more vulnerable) building classes leads to a reduction of $38 \%$ (from 551 to 340 ) and $22 \%$ (from 
2564 to 2003) in the expected value of people at risk for Villa and Mud and Wood buildings, respectively. This means that the structural retrofitting mitigation proposed produced a significant effect on the estimated number of people at risk. The breakdown (in percentage) of houses situated within the inundation foot print is $11 \%, 18 \%$ and $71 \%$ for Condominium, Villa and Mud and Wood structures, respectively, which can be compared to 5\%, $49 \%$ and $46 \%$ for the entire case study area. This means that the percentage of Mud and Wood buildings is larger in the flood-prone areas compared to the rest of the case study area. Given the informal and spontaneous nature of this type construction, it is logical to expect that the site of the building was not chosen based on formal and sound criteria.

The same calculations are repeated by considering also the prevision of a floodplain storage. Figure 13 illustrates the expected value of number of people affected by flooding per year and per household from Eq. 3. Figure 13a maps the expected value of the number of people affected by flooding in the as-built configuration, and Fig. 13b maps the same risk metric after the application of the above-mentioned structural upgrading strategies. The results are obtained herein by integrating the fragility curves reported in Figs. 10 and 11 with the hazard curves that consider the presence of the floodplain storage, reported in Fig. 7b. It can be observed that the number of people affected by flooding in the sub-windows a3-b3, a4-b4 and a5-b5 is reduced with respect to the same sub-windows in Fig. 12. This result can be attributed directly to the presence of the floodplain storage. In fact, as mentioned in paragraph 3.2.4, the presence of the floodplain storage leads to a reduction of the flooded areas in the catchment B1. Moreover, considering the structural upgrading in this case (paired up with the flood plain storage) results in a reduction in the expected value

(a)

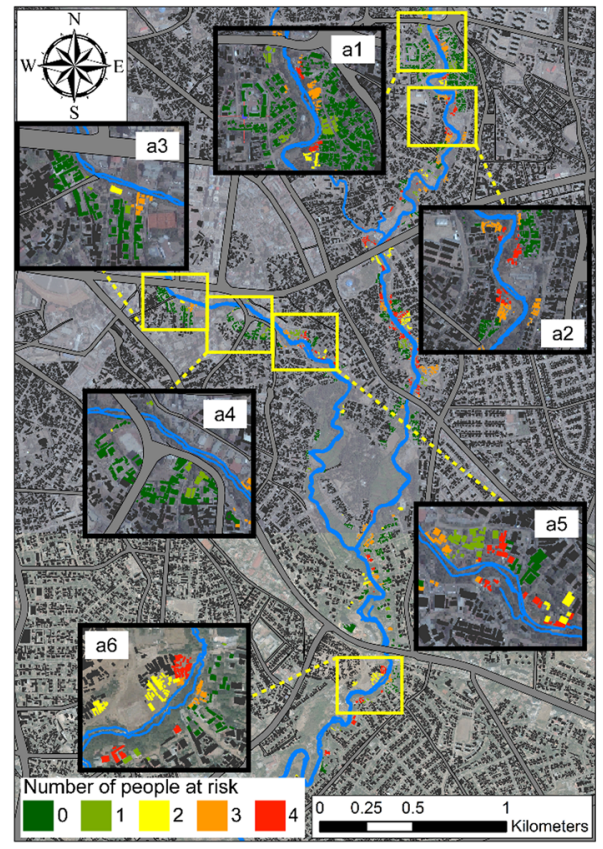

(b)

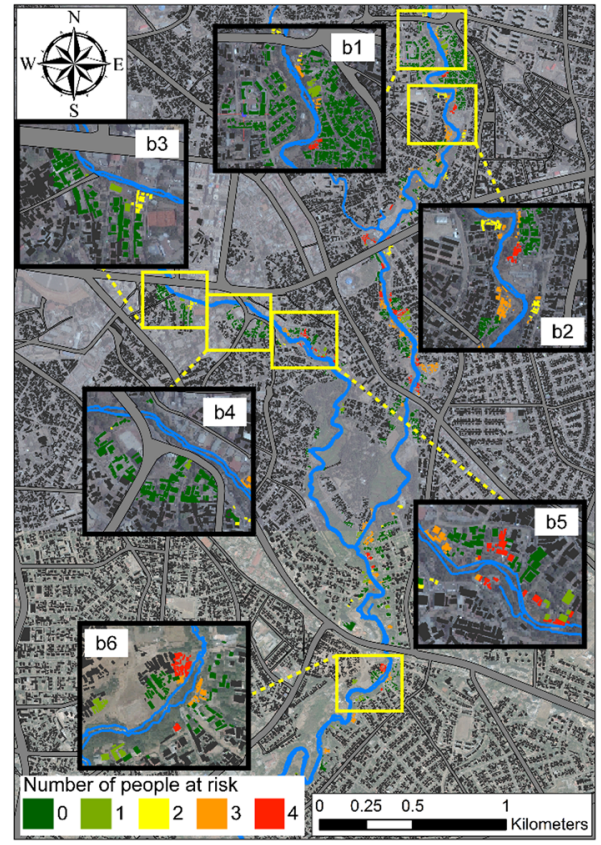

Fig. 13 Mapping the number of people at risk per each building considering the application of floodplain storage for $\mathbf{a}$ actual configuration of buildings and $\mathbf{b}$ upgrading of structures 
Table 3 Expected number of people at risk (flood plain storage envisioned)

\begin{tabular}{|c|c|c|c|}
\hline Building typology & Buildings at risk & $\begin{array}{l}\text { Maximum number of } \\
\text { people at risk }\end{array}$ & $\begin{array}{l}\text { Expected number of } \\
\text { people at risk (Eq. 3) }\end{array}$ \\
\hline \multicolumn{4}{|c|}{ W/o structural upgrading, with floodplain storage } \\
\hline Condominium & 283 & 1132 & 177 \\
\hline Villa & 465 & 1860 & 471 \\
\hline Mud and Wood & 1840 & 7360 & 2469 \\
\hline \multicolumn{4}{|c|}{ With structural upgrading, with floodplain storage } \\
\hline Condominium & 283 & 1132 & 177 \\
\hline Villa & 465 & 1860 & 287 \\
\hline Mud and Wood & 1840 & 7360 & 1908 \\
\hline
\end{tabular}

of number of people at risk not only in the northern part of the area but also in the southern part (i.e. sub-windows a6-b6). Finally, it is worth noting that the northeastern part of the case study area is not benefitting from the presence of flood plain storage. This is expected because the flood plain storage is going to located on catchment $\mathrm{B}_{1}$ (i.e., the catchment feeding the river coming from northwest).

Table 3 reports the expected value of people at risk per year in the entire case study area considering the construction of an on-stream flood plain storage (to be compared with Table 2 which did not envision the addition of a flood plain storage). As far as it regards the Condominium buildings, the total number of buildings located in flooded areas remains invariant. However, there is a reduction in the expected number of people at risk with respect to the current configuration. Considering that the Condominium buildings were not subjected to structural upgrading, the reduction of $14 \%$ can be attributed to a reduction in the flooding hazard due to the presence of the flood plain storage.

As far as it regards the upgraded Villa and Mud and Wood Buildings in the case where the flood plain storage is envisioned, reduction of $14 \%$ (from 551 to 471 ) and $4 \%$ (from 2564 to 2469 ) can be observed with respect to the case where structural upgrading techniques are not applied (Table 2). The application of the structural upgrading strategies paired up with the envision of the flood plain storage leads to overall reduction of number of people affected by flooding of 48\% (from 551 to 287) and 26\% (from 2564 to 1908), for Villa and Mud and Wood buildings, respectively. The overall reduction of exposure to flooding for the residential areas due to the paired application of the structural upgrading and the flood pair storage is $28 \%$. The contribution of the flood plain storage to the overall reduction in the flood exposure in the residential areas is estimated as $6 \%$ and the contribution of the structural upgrading being estimated as $22 \%$.

\subsection{Flood risk zoning}

Applying the methodology presented in the paragraph 2.2, flood risk zoning for the buildings that fall in the flood-prone area can be carried out. The acceptable collapse probability $P_{\mathrm{o}}$ is herein taken to be equal to $10 \%$ in a prescribed service lifetime ( $t$ in Eq. 2 ). The service lifetime is assumed to last for 5, 10 and 30 years for Mud and Wood, Villa and Condominium buildings, respectively. These correspond to return period $T_{\mathrm{R}}$ equal to $47.46,94.91$ and 284.74 years for the three above-mentioned buildings in order. Finally, the acceptable 
(a)

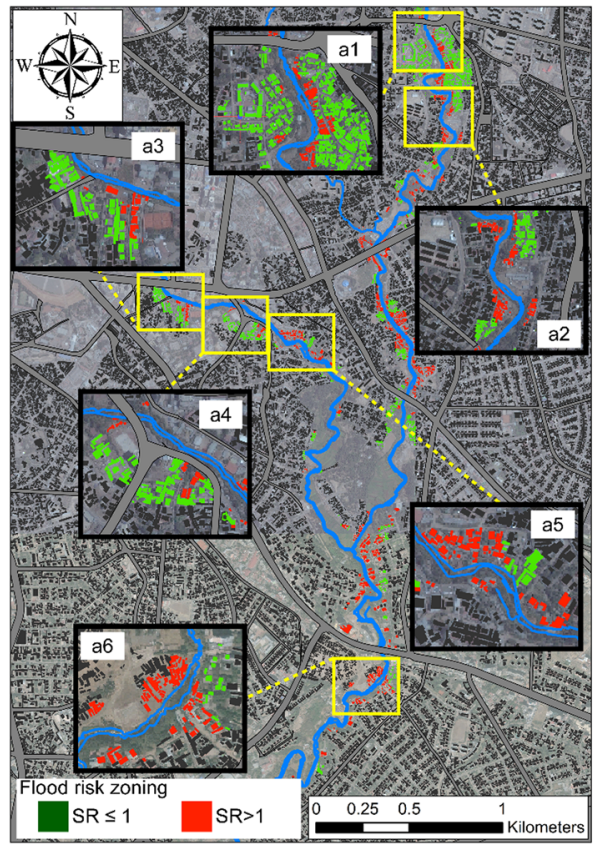

(b)

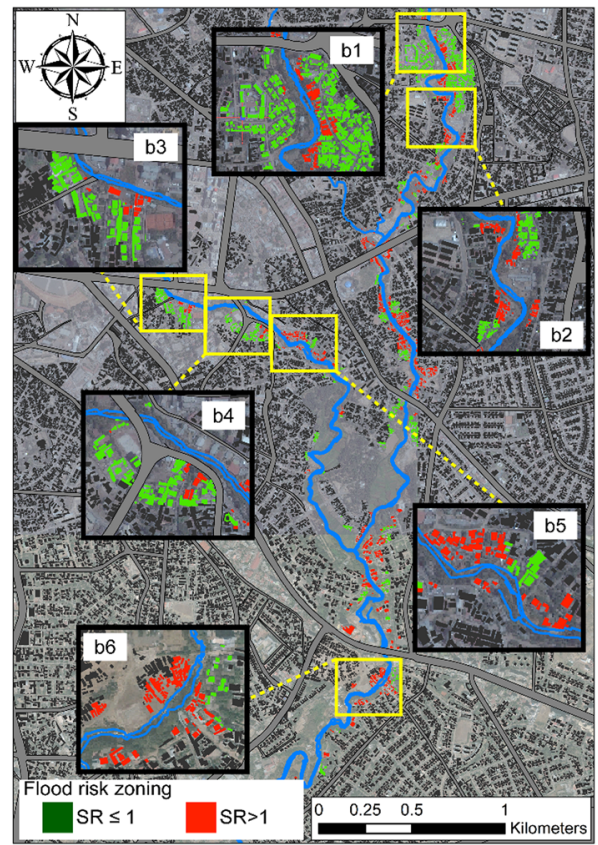

Fig. 14 Flood risk zoning (no flood plain storage) a actual configuration of buildings and $\mathbf{b}$ retrofitting of structures

Table 4 Number of buildings and people living in buildings with SR $>1$

\begin{tabular}{|c|c|c|c|}
\hline Building typology & Buildings at risk & Buildings with $\mathrm{SR} \leq 1$ & $\begin{array}{l}\text { People living in } \\
\text { buildings with } \\
\text { SR }>1\end{array}$ \\
\hline \multicolumn{4}{|c|}{ Actual configuration (reference case) } \\
\hline Condominium & 283 & 139 & 556 \\
\hline Villa & 465 & 220 & 880 \\
\hline Mud and Wood & 1840 & 870 & 3480 \\
\hline \multicolumn{4}{|c|}{ With structural upgrading, w/o floodplain storage } \\
\hline Condominium & 283 & 139 & 556 \\
\hline Villa & 465 & 181 & 724 \\
\hline Mud and Wood & 1840 & 844 & 3376 \\
\hline
\end{tabular}

rate of exceedance $\lambda_{\mathrm{o}}$ in Eq. 4 is calculated from Eq. 2 to be equal to 0.02, 0.01 and 0.0035, for Mud and Wood, Villa and Condominium buildings, respectively.

Figure $14 \mathrm{a}, \mathrm{b}$ shows the results in terms of the demand to capacity safety ratio SR (the index LS is dropped since it is reported only for the collapse limit state) for the initial configuration (i.e., without floodplain storage and as-built structural configuration) and for the case in which structural upgrading is applied, respectively. With respect to the current configuration in Fig. 14a (the reference case), improvement in the indicator (i.e., red buildings 
(a)

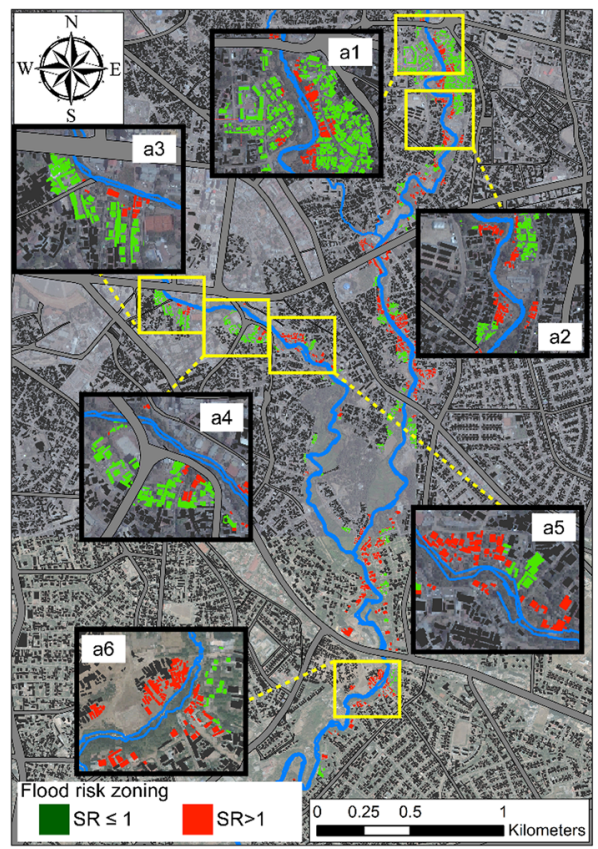

(b)

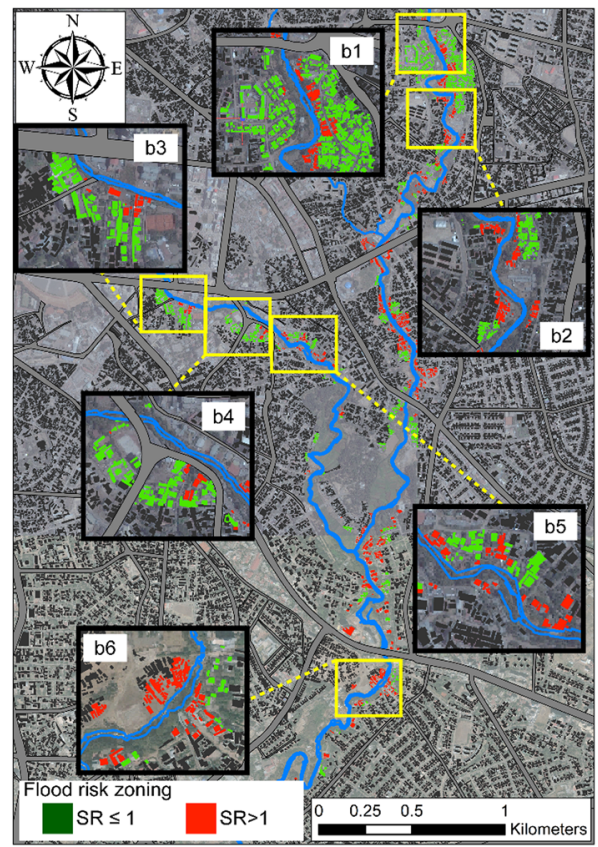

Fig. 15 Flood risk zoning considering the floodplain storage a actual configuration of buildings and $\mathbf{b}$ upgrading of structures

with $\mathrm{SR}>1$ are replaced with green buildings with $\mathrm{SR} \leq 1$ ) can be observed in practically all the sub-windows. Table 4 reports the expected value of buildings and people with SR greater than one in the case study area. The results demonstrate that, due to implementation of the structural upgrading (in the absence of flood plain storage), the number of buildings at risk ( $\mathrm{SR}>1)$ is reduced by $17 \%$ and $3 \%$, for Villa and Mud and Wood buildings, respectively. This is while the overall reduction in exposure to flooding is estimated as $5 \%$ for all the residential buildings in the case study area.

Table 5 Number of buildings and people living in buildings with $\mathrm{SR}>1$ for the case where the flood plain storage is envisioned

\begin{tabular}{lccc}
\hline Building typology & Buildings at risk & $\begin{array}{l}\text { Buildings } \\
\text { with SR }>1\end{array}$ & $\begin{array}{l}\text { People } \\
\text { with } \\
\text { SR }>1\end{array}$ \\
\hline \multicolumn{2}{l}{ W/o structural upgrading, with floodplain storage } \\
Condominium & 283 & 139 & 556 \\
Villa & 465 & 208 & 832 \\
Mud and Wood & 1840 & 852 & 3408 \\
With structural upgrading, with floodplain storage & \\
Condominium & 283 & 139 & 556 \\
Villa & 465 & 175 & 700 \\
Mud and Wood & 1840 & 815 & 3260 \\
\hline
\end{tabular}


Figure 15a, b shows the results in terms of indicator SR for the case in which the floodplain storage is considered, for the original structural configuration and when the upgrading is applied, respectively. Figure $15 \mathrm{~b}$ shows visible improvement with respect to Fig. 15a (i.e., red buildings transformed into green buildings) for zones a2-b2, a4-b4, a5-b5 and a6-b6. Table 5 reports the exposure results (number of buildings and number of people in buildings with $\mathrm{SR}>1$ ). It can be observed that structural upgrading (in the presence of flood plain storage) helps in reducing the number of people living in houses with SR $>1$ by $16 \%$ and $4 \%$, for Villa and Mud and Wood buildings, respectively. Overall, structural upgrading (in the presence of flood plain storage) reduces the exposure in the residential areas of the case study area by around 6\%. Comparing the results in Tables 4 and 5 shows that the flood plain storage alone leads to a very small reduction of the risk.

\subsection{Discussion}

The results of the risk zoning approach in Tables 4 and 5 (obtained by calculating the number of people living in buildings for which the risk of collapse due to flooding exceeds a prescribed acceptable level) are more conservative with respect to the values calculated through the rigorous approach reported in Tables 2 and 3 (by directly calculating the expected value of the number of people affected by buildings that collapse due to flooding from Eq. 3). Nevertheless, the risk zoning methodology allows for a fast screening of the flood-prone areas. Another useful aspect of fast risk zoning is that it enables the analyzer to perform a preliminary screening and ranking of alternative viable mitigation strategies. The mitigation measures have a greater impact in the northern part of the case study area before the junction where the two main streamlines B1 and B2 are still distinct.

Based on the previous results, if any financial resource is available for the mitigation of the flood risk, the priority is to act on the northern part of the case study area; in fact, the application of any mitigation solution would guarantee a satisfactory reduction of losses. On the contrary, a relocation of the buildings that fall in the river bed in the southern part of the case study area (downstream) could be more suitable.

Results in Tables 2, 3, 4 and 5 and Figs. 12, 13, 14 and 15 also emphasize that the main benefit is obtained for Villas with respect to Mud and Wood structures. This can be attributed to two factors: (a) the collapse fragility curves in Fig. 11a, b indicate that the upgrading strategies are effective only for flood depths less than $1.0 \mathrm{~m}$, and Villas are subjected to relatively more modest flood depths since they are generally located farther away from the river with respect to Mud and Wood buildings Fig. 8c; (b) it can be observed from Fig. $11 \mathrm{a}, \mathrm{b}$ that the upgrading strategies are more effective for the villas compared to the Mud and Wood buildings.

As mentioned above, the structural (addition of flood plain storage) and non-structural (application of structural upgrading strategies) mitigation measures can be compared in terms of the resulting reduction in flood exposure. It can be observed that the structural upgrading - in this specific case - is more effective with respect to the addition of a flood plain storage. This can be attributed to two reasons: (a) the dimension of the storage is limited by the dense urban built environment in the case study area (located in downtown Addis); and (b) only the northwest streamline B1 seems to benefit from the presence of the storage (as opposed to structural upgrading which is effective wherever applied). 


\section{Conclusion}

An integrated modular approach to flood risk assessment and flood risk zoning in a portfolio composed of different structural typologies is proposed. This approach integrates hazard modeling, exposure identification and vulnerability assessment through fragility modeling, in order to generate flooding risk maps and flood risk zoning maps. Flooding risk maps quantify and localize the expected number of buildings and people at risk, while flood risk zoning maps allow fast screening of the risk acceptability in the case study area. The proposed methodology, which is inspired by the performance-based engineering approach, manages to tackle two main challenges: (1) the lack or scarcity of data which is addressed by propagating uncertainties in a probabilistic framework; and (2) the presence of communication barriers with the stakeholders, which is hopefully overcome by providing maps and illustrative results. Furthermore, the modular structure of the methodology facilitates implementation by reducing it into a series of smaller and easier-to-implement single tasks.

Flood risk assessment is carried out through a step-by-step procedure resulting in both risk maps and risk zoning. The first step consists of a preliminary screening for the identification of the residential flooding risk hotspots. In the next step, the buildings' footprints and census information are collected for each risk hotspot identified. Then, the inundation maps for different return periods are calculated, and hazard curves corresponding to the centroid of each building are derived from the hazard maps. For each structural typology within the portfolio, identified through the UMT classification, analytical fragility curves are computed. The integration of hazard, vulnerability and exposure results in the risk and safety ratio zoning maps. The methodology presented is also employed to assess the impact on risk of different structural and non-structural mitigation strategies. It is worth noting that the proposed methodology can be implemented using available data from the web. Furthermore, it has the potential to be integrated in open-source loss modeling frameworks.

The case study area is a neighborhood in Addis Ababa downtown. The flood risk has been assessed and the efficiency of two mitigation strategies has been studied: (a) an online floodplain storage (i.e. hydraulic structural measure) and (b) the potential structural upgrading to improve the flooding vulnerability of buildings (i.e. hydraulic non-structural measures).

It has been observed for the case study area that the hydraulic non-structural measures are the most effective. On the other hand, the benefit of the floodplain storage is limited by its size due to the constraints exercised by the surrounding dense urban environment. The proposed mitigation strategies have a good impact on the northern part of the case study area; meanwhile, the southern part remains critical and alternative mitigation strategies such as relocation should be considered.

Finally, it is worth stating that the proposed methodology for fast risk zoning can be adopted also considering transportation infrastructure, such as bridges, that are severely exposed to riverine flooding (Pregnolato 2019). In order to make such implementation possible, the vulnerability of the infrastructure in question to fluvial flooding needs to be quantified through flood fragility functions for various relevant and specifically defined limit states.

Acknowledgements The authors would like to mention the passing away of the last author, the late Prof. Paolo Gasparini, in July 2016. This work was almost completed before his passing away except for the editorial modifications. He has been an excellent scientist and the perfect leader for CLUVA Project. His vision, his scientific approach and his passion for interdisciplinary research have been our beacon of light in the preparation of this work and will continue to inspire us. This work was supported in part by the European 
Commission's seventh framework program Climate Change and Urban Vulnerability in Africa (CLUVA), FP7-ENV-2010, Grant No. 265137 and the National Operative Program Project METROPOLIS 2014-16.

Open Access This article is distributed under the terms of the Creative Commons Attribution 4.0 International License (http://creativecommons.org/licenses/by/4.0/), which permits unrestricted use, distribution, and reproduction in any medium, provided you give appropriate credit to the original author(s) and the source, provide a link to the Creative Commons license, and indicate if changes were made.

\section{Appendix A}

The flood hydrograph was obtained using the WFIUH-1par methodology (Grimaldi et al. 2012). The WFIUH incorporates the spatial distribution of the hillslope and channel runoff dynamics at the basin scale into the instantaneous unit hydrograph (IUH) by means of the fully distributed residency time function or width function (Rodríguez-Iturbe and Rinaldo 1997 ) that is calibrated using physically based surface flow velocity parameters. Net rainfall was computed by using the CN4GA model (Grimaldi et al. 2013).

Using WFIUH-1 par methodology with a 90-m DEM, the IUH for the basins is obtained. Therefore, applying the convolution integration, it is possible to derive the flood event hydrographs for different return periods.

The time of concentration $\left(T_{\mathrm{C}}\right)$ is calculated by means the NRCS (1997) relation, developed for small rural basins and commonly used in combination with CN SCS and NRCS methods for the estimation of WFIUH-1.

\section{Appendix B}

The continuity equation is for a flow is:

$$
\frac{\mathrm{d} W}{\mathrm{~d} t}=q_{\mathrm{in}}-q_{\mathrm{out}}
$$

where $W$ is the volume of the storage and $q_{\text {in }}$ and $q_{\text {out }}$ are the incoming hydrograph and the outflow hydrograph, respectively. Let $S$ be the total surface of the floodplain storage and $h$ be the water depth inside the storage, then $\mathrm{W}$ can be expressed as below:

$$
W=S \cdot h
$$

The outflow hydrograph can be expressed through the outlet formula:

$$
q_{\text {out }}=\mu \cdot \sigma \cdot \sqrt{2 \cdot g \cdot h}
$$

where $\mu$ is the discharge coefficient (generally assumed to be equal to 0.61 according to Daugherty and Franzini 1965); $\sigma$ is the outlet area, that is variable with the return period considered in order to fill up the entire capacity of the storage; $g$ is the gravity acceleration (i.e. $9.81 \mathrm{~m} / \mathrm{s}^{2}$ ).

Deriving $\mathrm{h}$ from 7 and substituting it in 5, a new expression of the total flood volume is obtained:

$$
W=k \cdot q_{\text {out }}^{2}
$$

where $k$ is the storage constant of the floodplain storage and is equal to:

$$
k=\frac{S}{2 \cdot g \cdot \mu^{2} \cdot \sigma^{2}}
$$


Substituting 8 in 5 , it is possible to obtain the differential equation of the on-line floodplain storage:

$$
2 \cdot k \cdot q_{\text {out }} \cdot \frac{\mathrm{d} q_{\text {out }}}{\mathrm{d} t}=q_{\text {in }}-q_{\text {out }}
$$

This equation is generally solved by means finite differences schemes. Given the initial flow discharge $q_{\text {in }}$, Eq. 10 leads to evaluation of the outflow hydrograph to consider for the two-dimensional propagation.

\section{References}

Apel H, Aronica GT, Kreibich H, Thieken AH (2009) Flood risk analyses-how detailed do we need to be? Nat Hazard 49(1):79-98

Aronica G, Tucciarelli T, Nasello C (1998) 2D multilevel model for flood wave propagation in flood-affected areas. J Water Resour Plan Manag 124(4):210-217

Bates PD, De Roo APJ (2000) A simple raster-based model for flood inundation simulation. J Hydrol 236(1):54-77

Bates PD, Horritt MS, Aronica G, Beven K (2004) Bayesian updating of flood inundation likelihoods conditioned on flood extent data. Hydrol Process 18(17):3347-3370

Biscarini C, Di Francesco S, Nardi F, Manciola P (2013) Detailed simulation of complex hydraulic problems with macroscopic and mesoscopic mathematical methods. Math Prob Eng, vol 2013, Article ID 928309. https://doi.org/10.1155/2013/928309

Carozza S, De Risi R, Jalayer F (2013) D2.5-Guideline to decreasing physical vulnerability in the three considered cities. CLUVA project-Climate Change and Urban Vulnerability in Africa. http://www. cluva.eu/deliverables/CLUVA_D2.5.pdf. Accessed 01 Oct 2018

Carozza S, Jalayer F, De Risi R, Manfredi G, Mbuya E (2015) Comparing alternative flood mitigation strategies for non-engineered masonry structures using demand and capacity fac-tored design. In: 12th International conference on applications of statistics and probability in civil engineering, ICASP12, July 12-15, Vancouver, Canada

Cavan G, Lindley S, Yeshitela K, Nebebe A, Woldegerima T, Shemdoe R, Kibassa D, Pauleit S, Renner R, Printz A, Buchta K, Coly A, Sall F, Ndour NM, Ouédraogo Y, Samari BS, Sankara BT, Feumba RA, Ngapgue JN, Ngoumo MT, Tsalefac M, Tonye E (2012) Green infrastructure maps for selected case studies and a report with an urban green infrastructure mapping methodology adapted to African cities CLUVA project deliverable D2.7. http://www.cluva.eu/deliverables/CLUVA_D2.7.pdf. Accessed 01 Oct 2018

Cavan G, Lindley S, Jalayer F, Yeshitela K, Pauleit S, Renner F, Gill S, Capuano P, Nebebe A, Woldegerima T, Kibassa D (2014) Urban morphological determinants of temperature regulating ecosystem services in two African cities. Ecol Ind 42:43-57

Cobby DM, Mason DC, Horritt MS, Bates PD (2003) Two-dimensional hydraulic flood modelling using a finite-element mesh decomposed according to vegetation and topographic features derived from airborne scanning laser altimetry. Hydrol Process 17(10):1979-2000

Cornell CA, Jalayer F, Hamburger RO, Foutch DA (2002) Probabilistic basis for 2000 SAC federal emergency management agency steel moment frame guidelines. J Struct Eng 128(4):526-533

CRED (2012) Disaster data: a balanced perspective, Report 299. Centre for Research on the Epidemiology of Disasters. http://cred.epid.ucl.ac.be/f/CredCrunch29.pdf. Accessed 01 April 2015

Daugherty RL, Franzini JB (1965) Fluid mechanics, 6th edn. McGraw-Hill, New York, pp 338-349

De Martino G, De Paola F, Fontana N, Marini G, Ranucci A (2012) Experimental assessment of level pool routing in preliminary design of floodplain storage. Sci Total Environ 416:142-147

De Paola F, Giugni M, Topa ME, Bucchignani E (2014) Intensity-duration-frequency (IDF) rainfall curves, for data series and climate projection in African cities. SpringerPlus 3(1):133

De Risi R, Jalayer F, De Paola F, Iervolino I, Giugni M, Topa ME, Mbuya E, Kyessi A, Manfredi G, Gasparini P (2013a) Flood risk assessment for informal settlements. Nat Hazards 69(1):1003-1032

De Risi R, Jalayer F, Iervolino I, Manfredi G, Carozza S (2013b) VISK: a GIS-compatible platform for micro-scale assessment of flooding risk in urban areas. In COMPDYN, 4th ECCOMAS Thematic 
conference on computational methods in structural dynamics and earthquake engineering. Kos Island, Greece

De Risi R, Jalayer F, De Paola F, Giugni M (2014) Probabilistic delineation of flood-prone areas based on a digital elevation model and the extent of historical flooding: the case of Ouagadougou. Bol Geol Min 125(3):329-340

De Risi R, Jalayer F, De Paola F (2015) Meso-scale hazard zoning of potentially flood prone areas. J Hydrol 527:316-325

De Risi R, Jalayer F, De Paola F, Lindley S (2018a) Delineation of flooding risk hotspots based on digital elevation model, calculated and historical flooding extents: the case of Ouagadougou. Stoch Env Res Risk Assess 32(6):1545-1559

De Risi R, De Paola F, Turpie J, Kroeger T (2018b) Life cycle cost and return on investment as complementary decision variables for urban flood risk management in developing countries. Int J Disaster Risk Reduct 28:88-106

Degiorgis M, Gnecco G, Gorni S, Roth G, Sanguineti M, Taramasso AC (2012) Classifiers for the detection of flood-prone areas using remote sensed elevation data. J Hydrol 470:302-315

Di Baldassarre GD, Schumann G, Bates P (2009) Near real time satellite imagery to support and verify timely flood modelling. Hydrol Process 23(5):799-803

Dodov BA, Foufoula-Georgiou E (2006) Floodplain morphometry extraction from a high-resolution digital elevation model: a simple algorithm for regional analysis studies. IEEE Geosci Remote Sens Let 3(3):410-413

Domeneghetti A, Castellarin A, Brath A (2012) Assessing rating-curve uncertainty and its effects on hydraulic model calibration. Hydrol Earth Syst Sci 16(4):1191-1202

DRMFS (2006) Flash appeal for the 2006 Flood Disaster in Ethiopia. http://www.dppc.gov.et/downloadab le/reports/appeal/2006/Flood\%20Appeal\%20II\%20MASTER\%20Final.pdf

Fabio P, Aronica GT, Apel H (2010) Towards automatic calibration of 2-D flood propagation models. Hydrol Earth Syst Sci 14(6):911-924

Fleisher J, LaViolette A (1999) Elusive wattle-and-daub: finding the hidden majority in the archaeology of the Swahili. AZANIA: J Br Inst East Afr 34(1):87-108

FLO-2D Software, Inc (2004) FLO-2D ${ }^{\circledR}$ User's Manual, Nutrioso, Arizona. www.flo-2.com

Gallant JC, Dowling TI (2003) A multiresolution index of valley bottom flatness for mapping depositional areas. Water Resour Res. https://doi.org/10.1029/2002WR001426

Gill SE, Handley JF, Ennos AR, Pauleit S, Theuray N, Lindley SJ (2008) Characterising the urban environment of UK cities and towns: a template for landscape planning in a changing climate. Landsc Urban Plan 87:210-222

Grimaldi S, Petroselli A, Nardi F (2012) A parsimonious geomorphological unit hydrograph for rainfallrunoff modelling in small ungauged basins. Hydrol Sci J 57(1):73-83

Grimaldi S, Petroselli A, Romano N (2013) Green-ampt curve-number mixed procedure as an empirical tool for rainfall-runoff modelling in small and ungauged basins. Hydrol Process 27(8):1253-1264

HEC-RAS 4.1 (2010) Hydrological Engineering Center (HEC) river analysis system (RAS). United States Army Corps of Engineering (USACE). www.hec.usace.army.mil

Herslund LB, Jalayer F, Jean-Baptiste N, Jørgensen G, Kabisch S, Kombe W, Lindley S, Nyed PK, Pauleit S, Printz A, Vedeld T (2016) A multi-dimensional assessment of urban vulnerability to climate change in sub-Saharan Africa. Nat Hazards 82(2):149-172

Hoyois P, Guha-Sapir D (2012) Measuring the human and economic impact of disasters, Report 297. Center for Research on the Epidemiology of Disaster. http://www.bis.gov.uk/assets/foresight/docs/reducingrisk-management/supporting-evidence/12-1295-measuring-human-economic-impact-disasters.pdf. Accessed 01 April 2015

Jalayer F (2018) Visualizing the demand to capacity fator design format (DCFD) for safety-checking. In: Submitted for the proceedings of the 11th national conference of earthquake engineering, Los Angeles, June 25-29 June 2018

Jalayer F, De Risi R, Manfredi G, De Paola F, Topa ME, Giugni M, Bucchignani E, Mbuya E, Kyessi A, Gasparini P (2013a) From climate predictions to flood risk assessment for a portfolio of structures, 4881-4888. In: 11th International conference on structural safety \& reliability (ICOSSAR 2013), Columbia University, New York, NY, June 16-20, 2013

Jalayer F, De Risi R, Elefante L, Manfredi G (2013b) Robust fragility assessment using Bayesian parameter estimation. In: Paper presented at the Vienna congress on recent advances in earthquake engineering and structural dynamics 2013 (VEESD 2013), Vienna, Austria, 28-30 August

Jalayer F, De Risi R, De Paola F, Giugni M, Manfredi G, Gasparini P et al (2014) Probabilistic GIS-based method for delineation of urban flooding risk hotspots. Nat Hazards 73(2):975-1001 
Jalayer F, De Risi R, Kyessi A, Mbuya E, Yonas N (2015) Vulnerability of built environment to flooding in African Cities. In: Urban vulnerability and climate change in Africa. Springer International Publishing, pp 77-106

Jalayer F, Carozza S, De Risi R, Manfredi G, Mbuya E (2016) Performance-based flood safety-checking for non-engineered masonry structures. Eng Struct 106:109-123

Jalayer F, Aronica GT, Recupero A, Carozza S, Manfredi G (2018) Debris flow damage incurred to buildings: an in situ back analysis. J Flood Risk Manag 11:S646-S662

Khan S, Kelman I (2012) Progressive climate change and disasters: connections and metrics. Nat Hazards 61(3):1477-1481

Kottek M, Grieser J, Beck C, Rudolf B, Rubel F (2006) World map of the Köppen-Geiger climate classification updated. Meteorol Z 15(3):259-263

Kundzewicz ZW (2002) Non-structural flood protection and sustainability. Water Int 27(1):3-13

Manfreda S, Nardi F, Samela C, Grimaldi S, Taramasso AC, Roth G, Sole A (2014) Investigation on the use of geomorphic approaches for the delineation of flood prone areas. J Hydrol 517:863-876

Marco JB (1994) Flood risk mapping. Chapter 20. In: Rossi G, Harmancioğlu N, Yevjevich V (eds) Coping with floods, vol 257. Springer, Dordrecht, pp 353-373

Merz B, Thieken AH, Gocht M (2007) Flood risk mapping at the local scale: concepts and challenges. In: Begum S, Stive MF, Hall J (eds) Chapter 13 of flood risk management in Europe, vol 25. Springer, Dordrecht, pp 231-251

Nadal NC, Zapata RE, Pagán I, López R, Agudelo J (2010) Building damage due to riverine and coastal floods. J Water Resour Plan Manag 136(3):327-336

NRCS (National Research Conservation Service) (1997) Ponds-planning, design, construction. US Natural Resources Conservation Service, Washington DC. Agriculture Handbook no. 590-

O’Brien JS, Julien PY, Fullerton WT (1993) Two-dimensional water flood and mudflow simulation. J Hydraul Eng 119(2):244-261

Pauleit S, Duhme F (2000) Assessing the environmental performance of land cover types for urban planning. Landsc Urban Plan 52(1):1-20

Porter K, Kennedy R, Bachman R (2007) Creating fragility functions for performance-based earthquake engineering. Earthq Spectra 23(2):471-489

Pregnolato M (2019) Bridge safety is not for granted-a novel approach to bridge management. Eng Struct 196:109193

Rodríguez-Iturbe I, Rinaldo A (1997) Fractal river networks: chance and self-organization. Cambridge University Press, Cambridge

Sakijege T, Sartohadi J, Marfai MA, Kassenga GR, Kasala SE (2014) Assessment of adaptation strategies to flooding: a comparative study between informal settlements of Keko Machungwa in Dar es Salaam, Tanzania and Sangkrah in Surakarta, Indonesia. Jàmbá: J Disaster Risk Stud 6(1):1-10

Samela C, Manfreda S, De Paola F, Giugni M, Sole A, Fiorentino M (2016) DEM-based approaches for the delineation of flood-prone areas in an ungauged basin in Africa. J Hydrol Eng 21(2):06015010

Samela C, Albano R, Sole A, Manfreda S (2018) A GIS tool for cost-effective delineation of flood-prone areas. Comput Environ Urban Syst 70:43-52

Scawthorn C, Blais N, Seligson H, Tate E, Mifflin E, Thomas W, Murphy J, Jones C (2006a) HAZUS-MH Flood loss estimation methodology. I. Overview and flood hazard characterization. Nat Hazards Rev 7:60-71 (Special issue: multihazards loss estimation and HAZUS)

Scawthorn C, Flores P, Blais N, Seligson H, Tate E, Chang S, Mifflin E, Thomas W, Murphy J, Jones C, Lawrence M (2006b) HAZUS-MH flood loss estimation methodology. II. Damage and loss assessment. Nat Hazards Rev 7:72-81 (Special issue: multihazards loss estimation and HAZUS)

Schwarz J, Maiwald H (2008) Damage and loss prediction model based on the vulnerability of building types. In: 4th international symposium of flood defence, Toronto, Canada, May 6-8

Smith DI (1994) Flood damage estimation-a review of urban stage-damage curves and loss function. Water SA 20(3):231-238

Teng J, Jakeman AJ, Vaze J, Croke BF, Dutta D, Kim S (2017) Flood inundation modelling: a review of methods, recent advances and uncertainty analysis. Environ Model Softw 90:201-216

Thampapillai DJ, Musgrave WF (1985) Flood damage mitigation: a review of structural and nonstructural measures and alternative decision frameworks. Water Resour Res 21(4):411-424

Topa ME, Giugni M, De Paola F (2014) Off-stream floodplain storage: numerical modeling and experimental analysis. J Irrig Drain Eng 141(1)

UN-HABITAT, State of the World's Cities 2010/2011 (2010) Cities for all: bridging the urban divide, report in state of the world's cities. http://www.unhabitat.org/pmss/listItemDetails.aspx?publicationID=2917. Accessed 1 Apr 2015 
Yang TH, Chen YC, Chang YC, Yang SC, Ho JY (2015) Comparison of different grid cell ordering approaches in a simplified inundation model. Water 7(2):438-454

Publisher's Note Springer Nature remains neutral with regard to jurisdictional claims in published maps and institutional affiliations. 